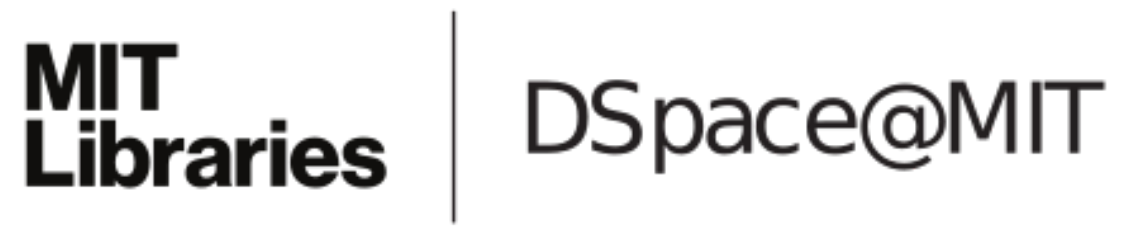

\author{
MIT Open Access Articles
}

Modeling the hydroclimatology of the midwestern

United States. Part 1: current climate

The MIT Faculty has made this article openly available. Please share how this access benefits you. Your story matters.

Citation: Winter, Jonathan M., and Elfatih A. B. Eltahir. "Modeling the Hydroclimatology of the Midwestern United States. Part 1: Current Climate." Climate Dynamics 38.3-4 (2012): 573-593

As Published: http://dx.doi.org/10.1007/s00382-011-1182-2

Publisher: Springer-Verlag

Persistent URL: http://hdl.handle.net/1721.1/104878

Version: Author's final manuscript: final author's manuscript post peer review, without publisher's formatting or copy editing

Terms of use: Creative Commons Attribution-Noncommercial-Share Alike 


\title{
Modeling the hydroclimatology of the midwestern United States. Part 1: current climate
}

\author{
Jonathan M. Winter • Elfatih A. B. Eltahir
}

Received: 3 August 2010/Accepted: 30 August 2011/Published online: 21 September 2011

(C) Springer-Verlag (outside the USA) 2011

\begin{abstract}
An ensemble of six 22-year numerical experiments was conducted to evaluate the ability of Regional Climate Model version 3 (RegCM3) to simulate the energy and water budgets of the midwestern United States. RegCM3 was run using two surface physics schemes: Integrated Biosphere Simulator (IBIS) and BiosphereAtmosphere Transfer Scheme 1e (BATS1e), and two convective closure assumptions: Fritsch \& Chappell (FC80) and Arakawa \& Schubert (AS74). Boundary conditions were provided by the National Centers for Environmental Prediction-Department of Energy Reanalysis 2 dataset and the ECHAM5 general circulation model. A companion paper examines the American Midwest under future climate scenarios. Overall, the model that reproduces the observed seasonal cycles of the midwestern United States climate system best is RegCM3 using IBIS and the AS74 convective closure assumption. IBIS simulates shortwave radiation more accurately, while BATS1e simulates longwave radiation more accurately. Summer two-meter air temperature is overestimated by the combination of IBIS and the FC80 convective closure assumption. All models contain a wet bias and overestimate evapotranspiration during the spring. Total runoff, surface runoff, groundwater runoff, and root zone soil moisture are best simulated by RegCM3 using IBIS and the AS74 convective closure assumption. While BATS1e does capture the seasonal cycle of total runoff, gross errors in the
\end{abstract}

J. M. Winter · E. A. B. Eltahir

Massachusetts Institute of Technology, Cambridge, MA, USA

Present Address:

J. M. Winter ( $\square)$

NASA Goddard Institute for Space Studies, New York, NY, USA

e-mail: jwinter@mit.edu; jwinter@giss.nasa.gov partitioning of total runoff between surface runoff and groundwater runoff exist. The seasonal cycle of root zone soil moisture simulated by RegCM3 using IBIS and the AS74 convective closure assumption is dry, but agrees with observations during the summer. The rest of the models underestimate root zone soil moisture.

Keywords Hydrology · Regional climate modeling · Midwestern United States

\section{Introduction}

Assessing the local impacts of climate change is vital to formulating intelligent adaptation strategies for the agricultural industry. Regional climate modeling is one method used to downscale general circulation model (GCM) output to societally relevant scales. Though limited by the use of boundary conditions and prescribed sea surface temperatures, regional climate models (RCMs) are able to represent important processes at sub-GCM resolutions. For example, Pal et al. (2004) used a regional climate model to quantify and describe European summer drying projected by the Prediction of Regional Scenarios and Uncertainties for Defining European Climate Change Risks and Effects (PRUDENCE) project, and Bell et al. (2004) used an RCM to assess regional changes in extreme climate events over California.

There have been numerous studies examining the ability of GCMs, RCMs, and probabilistic models to simulate the climate of the midwestern United States. Delworth et al. (2002) evaluated the Geophysical Fluid Dynamics Laboratory R30 coupled climate model used in Manabe et al. (2004) against observed temperature and precipitation data. The model simulated a large warm bias, $\approx 8^{\circ} \mathrm{C}$, and 
underestimated precipitation by $\approx 1 \mathrm{~mm}$ day $^{-1}$ over the American Midwest during the summer.

Wang (2005) explored future drought using data from 15 GCMs that participated in the Intergovernmental Panel on Climate Change (IPCC) Fourth Assessment Report. Precipitation was the only variable evaluated against observations; the bias in the 15-model precipitation average over the midwestern United States during the summer was between 1 and $2 \mathrm{~mm}_{\text {day }}{ }^{-1}$.

Seneviratne et al. (2002) analyzed four 1-year numerical experiments over the American Midwest using the National Center for Atmospheric Research (NCAR) Regional Climate Model (RegCM), and found that precipitation was overestimated by approximately $0.5 \mathrm{~mm}$ day $^{-1}$ during the months of March, April, and May. Precipitation was well modeled through the rest of the summer and underestimated slightly in September. Simulated values of evapotranspiration were in reasonable agreement with a 10-year climatology of evapotranspiration derived using an atmospheric and soil water balance; however, evapotranspiration was overestimated by $\approx 0.5 \mathrm{~mm} \mathrm{day}^{-1}$ in April and May.

One of the most complete assessments of a regional climate model over the midwestern United States was completed by Pal et al. (2000) using a modified version of RegCM. Simulated values for temperature, precipitation, outgoing longwave radiation, incident surface shortwave radiation, and precipitation were evaluated for six 1-year numerical experiments. Temperatures agreed well with observations throughout the year. Precipitation was modeled accurately on average, but was overestimated during the spring. Outgoing longwave radiation and incident surface shortwave radiation were similar to observations for practically all months examined.

The following sections detail two sets of control experiments that were conducted to assess and improve the ability of RegCM3-IBIS and RegCM3-BATS1e to simulate the surface energy and water budgets of the midwestern United States. This evaluation of RegCM3 is unique because of its extensive comparison to observationsincluding temperature, precipitation, evapotranspiration, shortwave radiation, longwave radiation, runoff, and soil moisture-and the use of multiple surface physics schemes, convective closure assumptions, and boundary conditions. In addition, these experiments provide the background and context for the companion paper that assesses the American Midwest under future climate scenarios.

\section{Model description and development}

Regional Climate Model version 3 (RegCM3) was chosen for this study because of its ability to accurately simulate the energy and water budgets of North America ( $\mathrm{Pal} 2001)$. RegCM3 is a 3-dimensional, sigma-coordinate, hydrostatic, compressible regional climate model originally created at NCAR and currently maintained at the International Centre for Theoretical Physics (ICTP). Brief descriptions of the surface physics and convective schemes used are provided below. Full documentation of RegCM3 can be found in Pal et al. (2007).

Biosphere-Atmosphere Transfer Scheme 1e (BATS1e) is a comprehensive model of land surface processes that can be run offline, coupled to a GCM, or coupled to RegCM3 (Dickinson et al. 1993). BATS1e simulates a single-layer canopy with two soil layers and one snow layer. Full documentation of BATS1e can be found in Dickinson et al. (1993).

Integrated Biosphere Simulator (IBIS), which was developed by Foley et al. (1996) at the University of Wisconsin-Madison, is a terrestrial biosphere model that uses a modular, physically consistent framework to perform integrated simulations of water, energy, and carbon fluxes. Full documentation of IBIS can be found in Foley et al. (1996). The coupling of IBIS to RegCM3 is described in Winter et al. (2009).

The parameterization of convection plays a central role in simulating precipitation. The Grell scheme is a basic representation of convection similar in structure to the Arakawa \& Schubert scheme (Arakawa and Schubert 1974), and models clouds as two steady-state circulations, an updraft and a downdraft (Grell et al. 1994).

The simplicity of the Grell scheme allows for two different closure assumptions. The quasi-equilibrium Arakawa \& Schubert closure (AS74) assumes that convection stabilizes the environment at the same rate that non-convective processes destabilize it (Grell et al. 1994), while the Fritsch \& Chappell (FC80) closure assumes that convection removes available buoyant energy at a user-defined timescale (Fritsch and Chappell 1980).

\section{Design of experiments}

All control experiments are centered at $40^{\circ} \mathrm{N}, 95^{\circ} \mathrm{W}$ and use a Rotated Mercator projection. The domain spans 100 points zonally, 60 points meridionally at a horizontal grid spacing of $60 \mathrm{~km}$, covering all of the United States as well as parts of Mexico and Canada (Fig. 1). Simulations were initialized April 1st, 1982 and allowed to spin-up for 21 months. The years evaluated (1984-2005) were chosen for maximum overlap with observational datasets. The region assessed is shown by the $4.0^{\circ} \times 5.5^{\circ}$ shaded box contained in Fig. 1, and was also chosen for maximum overlap with observational datasets. 


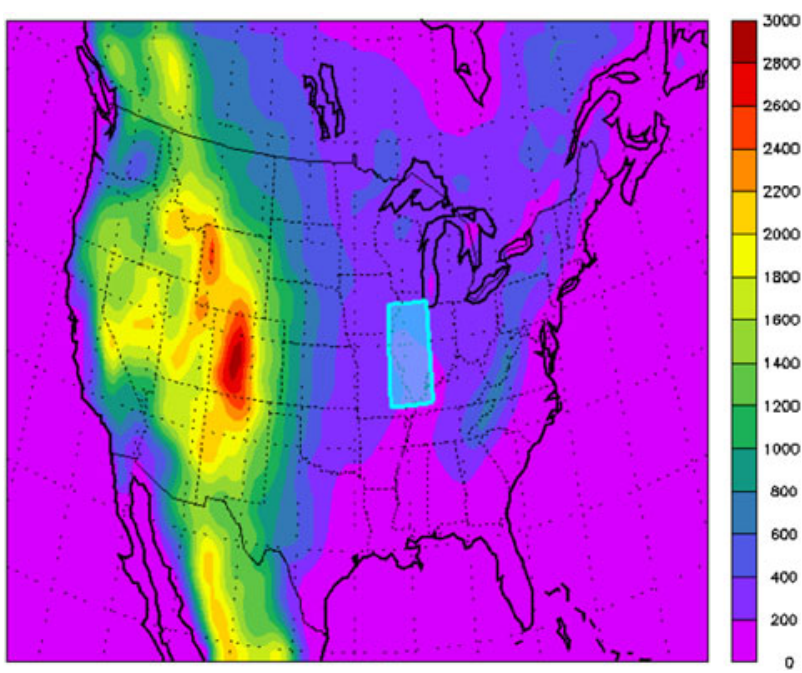

Fig. 1 Domain and topography $(\mathrm{m})$ of control experiments with a $4.0^{\circ} \times 5.5^{\circ}$ cyan shaded box delineating the extent of spatial averaging over the American Midwest

In RegCM3-BATS1e, vegetation classes were directly assigned using the Global Land Cover Characterization (GLCC) dataset of the United States Geological Survey (USGS) (1997). In RegCM3-IBIS, the potential global vegetation dataset of Ramankutty (1999) was used to initialize biomes, and then each grid box was populated with plant functional types (PFTs) based on the biome and two datasets: monthly mean climatology of temperature (New et al. 1999) and minimum temperature ever recorded at a location minus the average temperature of the coldest month (Bartlein 2000). Croplands were then defined in RegCM3-IBIS using the USGS GLCC dataset. Topography for both models was given by the USGS Global 30-arc Second Elevation dataset (1996) aggregated to a $0.5^{\circ} \times 0.5^{\circ}$ spatial resolution.

Although RegCM3-IBIS is capable of simulating dynamic vegetation, in all numerical experiments presented static vegetation was used. First, this creates a more consistent comparison between RegCM3-IBIS and RegCM3-BATS1e, which does not include vegetation dynamics. Second, the analyses conducted focus primarily on agricultural areas, which are not natural systems in which vegetation would be allowed to evolve. And finally, the time period examined, chosen for maximum overlap with observational datasets, is somewhat short for a reasonable simulation of dynamic vegetation.

At initialization, soil temperature was set by the surface temperature boundary condition and soil moisture was assigned based on vegetation type in RegCM3-BATS1e. Soil moisture, soil temperature, and soil ice in RegCM3IBIS were initialized using the April monthly average of the last year of a global 20 -year $0.5^{\circ} \times 0.5^{\circ}$ offline IBIS simulation. The monthly mean climatology variables required to run the offline version of IBIS are cloudiness, precipitation rate, relative humidity, temperature, wet days per month, near-surface wind speed, and temperature range, which are all products of the Climate Research Unit (CRU) Climatology 1.0 (CL1.0) dataset (New et al. 1999). Differences in the initialization of soil moisture and temperature were shown to be a relatively minor source of variability in the modeling results of similar experiments (Winter et al. 2009).

The National Aeronautics and Space Administration (NASA) Surface Radiation Budget (SRB) dataset, obtained from NASA Langley Research Center Atmospheric Science Data Center, was used to evaluate shortwave and longwave radiative fluxes (NASA 2006). Documentation of the NASA SRB dataset estimates errors in the shortwave and longwave radiation budgets to be approximately 5 and $10 \mathrm{~W} \mathrm{~m}^{-2}$, respectively. Observed values of the hydrologic cycle were derived from the regional $\left(\approx 10^{5} \mathrm{~km}^{2}\right)$ water balances of Yeh et al. (1998), which includes data from: the Midwest Climate Center, EarthInfo, Inc., the Illinois State Water Survey (ISWS), USGS, and the National Centers for Environmental Prediction (NCEP)/NCAR Reanalysis 1. Presented values for evapotranspiration in all figures were calculated by averaging the atmospheric and soil water balance estimates. Errors in determining evapotranspiration were found by Yeh et al. (1998) to be $\approx 10 \%$. Negative evapotranspiration estimates during the winter are primarily attributable to an underestimation in precipitation measurements (Yeh et al. 1998). Total runoff is based on USGS streamflow data and surface runoff is calculated by scaling observed precipitation using an empirically-derived surface runoff coefficient $(0.06)$ (Yeh 2003). Groundwater runoff was computed by taking the difference between total runoff and surface runoff. For clarity, all observations used to estimate evapotranspiration, as well as the evapotranspiration values themselves, are referred to as Illinois State Water Survey (ISWS) data. Temperature and precipitation values for the continental United States are provided by the Climate Research Unit (CRU) Time Series 2.1 (TS2.1) (Mitchell et al. 2004).

The number of soil layers and total soil depth in RegCM3-IBIS were changed in order to better represent the subsurface hydrology of the American Midwest. The default configuration for number of soil layers and total soil depth in IBIS is six and $4 \mathrm{~m}$, respectively. However, because no explicit representation for groundwater exists, this forces unsaturated soils to a depth of $4 \mathrm{~m}$. Observations show that the water table is rarely $4 \mathrm{~m}$ deep in the midwestern United States (Yeh et al. 1998). Accordingly, the bottom soil layer was removed from the model, leaving five soil layers and a total soil depth of $2 \mathrm{~m}$. Future developments of RegCM3-IBIS include adding a parameterization of groundwater similar to Yeh (2005). 


\subsection{NCEP-DOE Reanalysis 2}

In the first set of experiments, RegCM3-IBIS and RegCM3-BATS1e were forced using boundary conditions compiled from the NCEP-Department of Energy (DOE) Reanalysis 2 (NNRP2) dataset (Kanamitsu et al. 2002) under the exponential relaxation of Davies and Turner (1977). Sea surface temperatures (SSTs) were prescribed using the National Oceanic and Atmospheric Administration (NOAA) Optimum Interpolation SST (OISST) dataset, which has a spatial resolution of $1.0^{\circ} \times 1.0^{\circ}$ and is averaged on a weekly basis (Reynolds et al. 2002).

Previous numerical experiments revealed that both RegCM3-IBIS and RegCM3-BATS1e are sensitive to convective closure assumption (e.g. Martínez-Castro et al. 2006; Zanis et al. 2009; Tchotchou and Kamga 2010). To examine the model configuration variability of the NNRP2 control experiments, RegCM3-IBIS and RegCM3BATS1e were run using the Grell parameterization of convection with both the Fritsch \& Chappell (FC80) and the Arakawa \& Schubert (AS74) convective closure assumptions. This produced an ensemble of four simulations: RegCM3-IBIS using AS74 (IBIS-AS), RegCM3BATS1e using FC80 (BATS-FC), RegCM3-IBIS using FC80 (IBIS-FC), and RegCM3-BATS1e using AS74 (BATS-AS).

\subsection{ECHAM5 GCM}

While the NNRP2 dataset provides useful boundary conditions for assessing the ability of RegCM3-IBIS and RegCM3-BATS1e to simulate the current climate, it cannot describe future climate. General circulation models, however, are capable of producing unconstrained simulations of future climate. The ECHAM5 GCM (EH5OM) is a fully-coupled atmosphere-ocean general circulation model with a horizontal grid spacing of $1.875^{\circ} \times 1.875^{\circ}$. EH5OM is currently maintained at the Max Plank Institute for Meteorology in Germany; additional model details can be found in Roeckner et al. (2003). EH5OM was chosen based on its ability to accurately simulate the climate of the continental United States in the Intergovernmental Panel on Climate Change Fourth Assessment Report (Randall et al. 2007). Boundary conditions for 1982-2000 were derived from the twentieth century simulation with observed anthropogenic forcings (Roeckner et al. 2006a). Because the final year of the twentieth century simulation is 2000 , the last 5 years of boundary conditions (2001-2005) were compiled from a simulation of EH5OM under the A1B emissions scenario (Roeckner et al. 2006b). Boundary conditions are continuous as the A1B emissions scenario simulation used was initialized with the end of the twentieth century simulation used.
EH5OM experiments were run using the configuration for convection in RegCM3-IBIS and RegCM3-BATS1e that best simulated the hydroclimatology of the American Midwest in the NNRP2 experiments described above: IBIS-AS and BATS-FC.

\section{Results and discussion}

The performance of IBIS-AS, BATS-FC, IBIS-FC, and BATS-AS using NNRP2 and EH5OM boundary conditions over the American Midwest is described below. Presented results are $4.0^{\circ} \times 5.5^{\circ}$ spatial averages over the box contained in Fig. 1 unless otherwise noted. These simulations serve as the control experiments for a companion paper that examines the midwestern United States under a warmer climate.

\subsection{NCEP-DOE Reanalysis 2}

Figures 2, 3, 4, 5, and 6 present each variable using a pair of panels, where the left panel shows the NNRP2 control and observed seasonal cycles, and the right panel shows the difference between the NNRP2 control and observed seasonal cycles. Error bars showing 95\% confidence intervals calculated using the Student's t-distribution are included in seasonal cycle figures, and filled markers in difference figures denote simulated and observed confidence intervals that do not overlap.

IBIS-AS simulates the seasonal cycle of incident surface shortwave radiation best overall, as shown in Fig. 2. BATS-FC overestimates incident surface shortwave radiation in the summer (June, July, August) by as much as $23 \mathrm{~W} \mathrm{~m}^{-2}$ and underestimates incident surface shortwave radiation in the winter (December, January, February). During the summer months, the shortwave radiation budget is strongly affected by convective closure, where the FC80 convective closure assumption produces less clouds than the AS74 convective closure assumption (Fig. 2). In the winter, incident surface shortwave radiation is primarily a function of surface physics model. Absorbed surface shortwave radiation biases correspond with incident surface shortwave radiation biases, which implies an accurate simulation of surface albedo. Accordingly, IBIS-AS captures the observed seasonal cycle of absorbed surface shortwave radiation best. Incident top of atmosphere shortwave radiation is included for completeness and is modeled accurately.

Biases in two-meter air temperature are strongly correlated with inaccuracies in the shortwave radiation budget, and are therefore influenced by surface physics model throughout the year and by convective closure assumption during the summer (Fig. 3). IBIS-AS simulates two-meter 
(a)
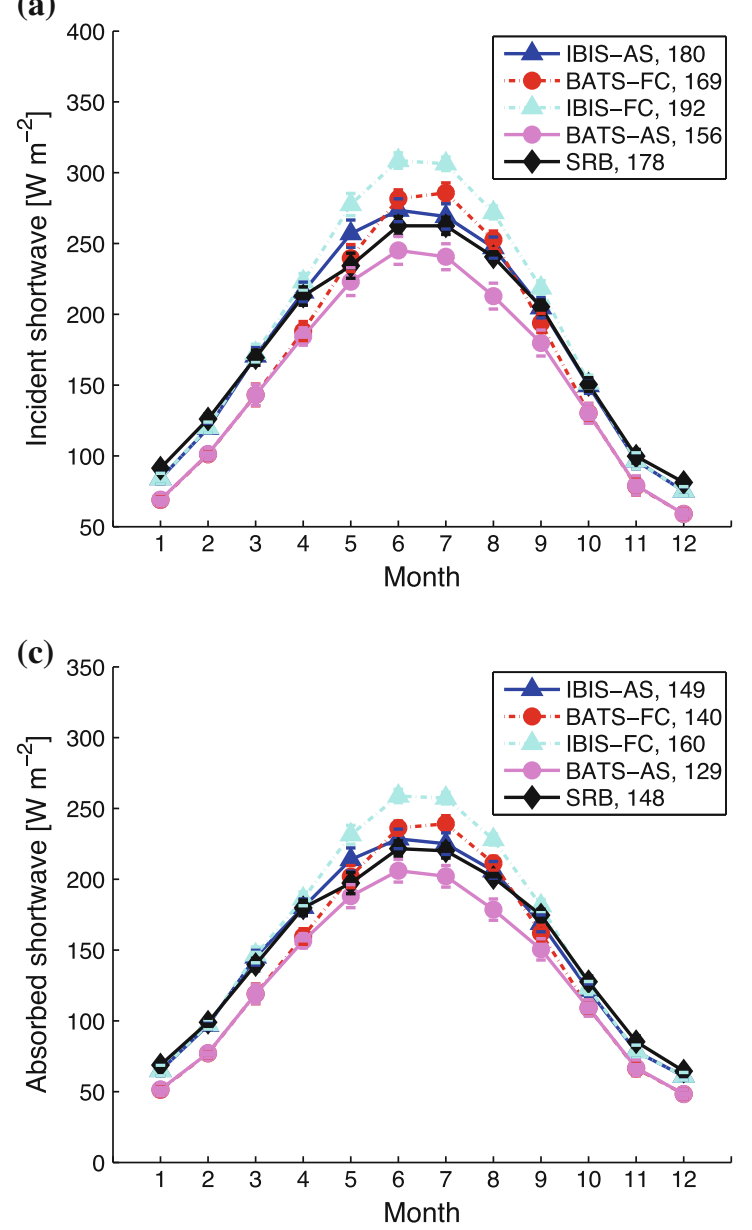

(6)

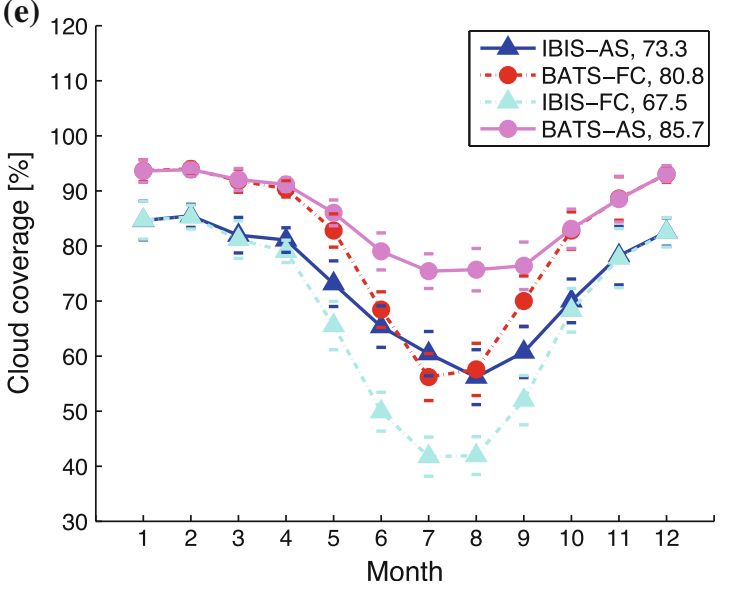

Fig. 2 NNRP2 control and observed seasonal cycles of: a incident surface shortwave radiation, $\mathbf{c}$ absorbed surface shortwave radiation, $\mathbf{e}$ percentage of maximum model fractional cloud cover (0.8), $\mathbf{f}$ incident top of atmosphere (TOA) shortwave radiation; and the difference between NNRP2 control and observed seasonal cycles of: $\mathbf{b}$ incident

air temperature best, with a slight warm bias in the winter and summer that peaks at $1.6^{\circ} \mathrm{C}$ in January. Two-meter air temperature is underestimated by BATS-FC by $2.5^{\circ} \mathrm{C}$
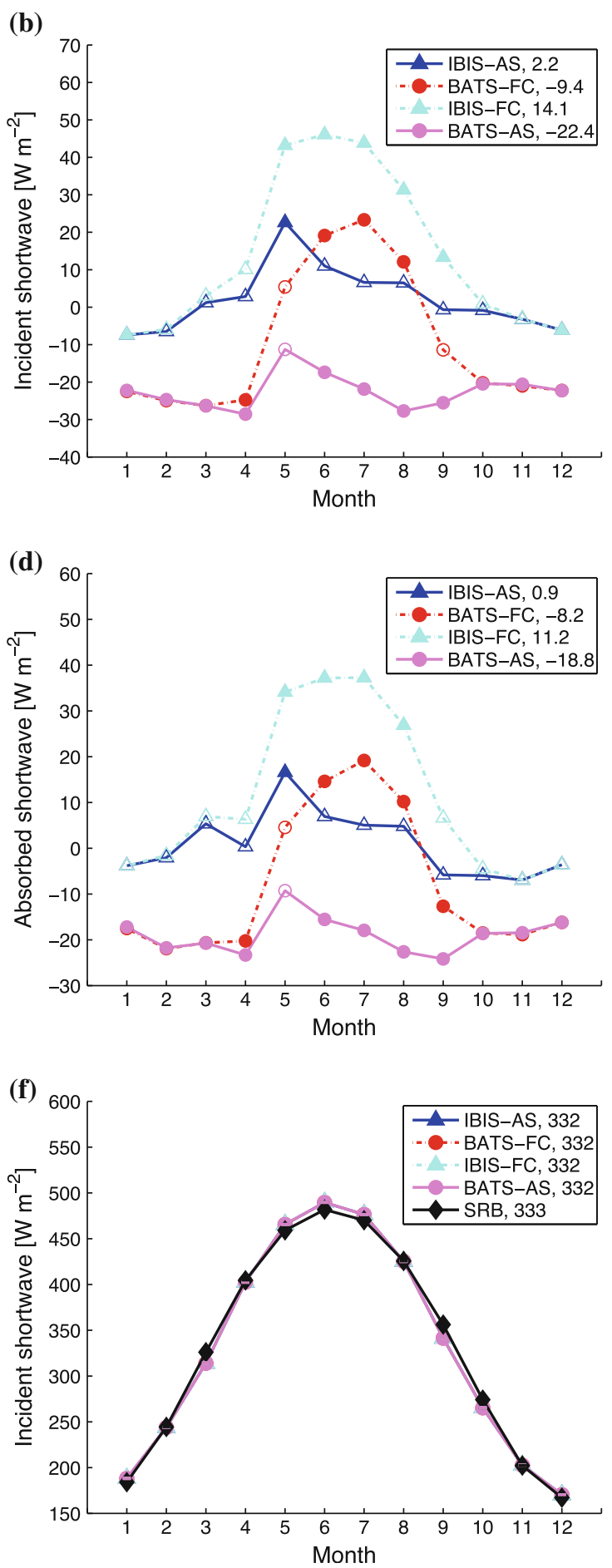

surface shortwave radiation, $\mathbf{d}$ absorbed surface shortwave radiation for 1984-2004. Error bars showing 95\% confidence intervals are included in panels (a, c, e, f), filled markers denote non-overlapping confidence intervals in panels (b, d), and annual averages for each variable examined are provided in the legend

during the spring (March, April, May). IBIS-FC overestimates summer two-meter air temperature by $3.0^{\circ} \mathrm{C}$. Twometer air temperature biases are comparable to those found 
(a)

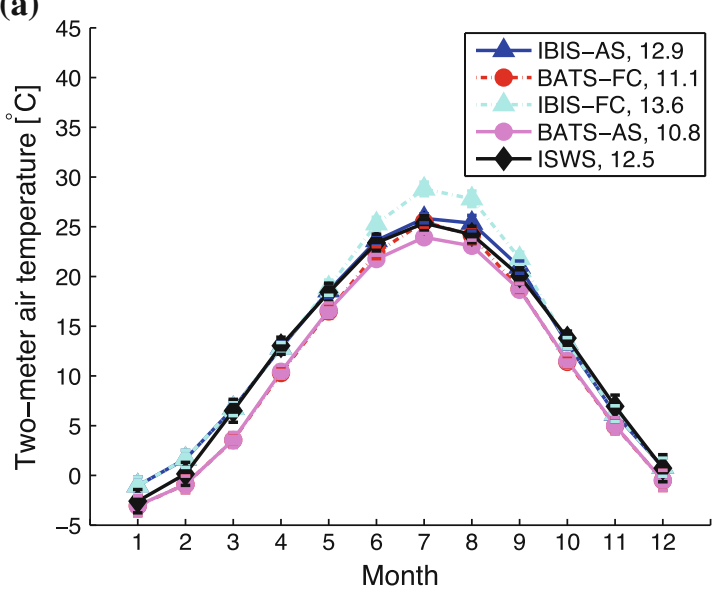

(c)

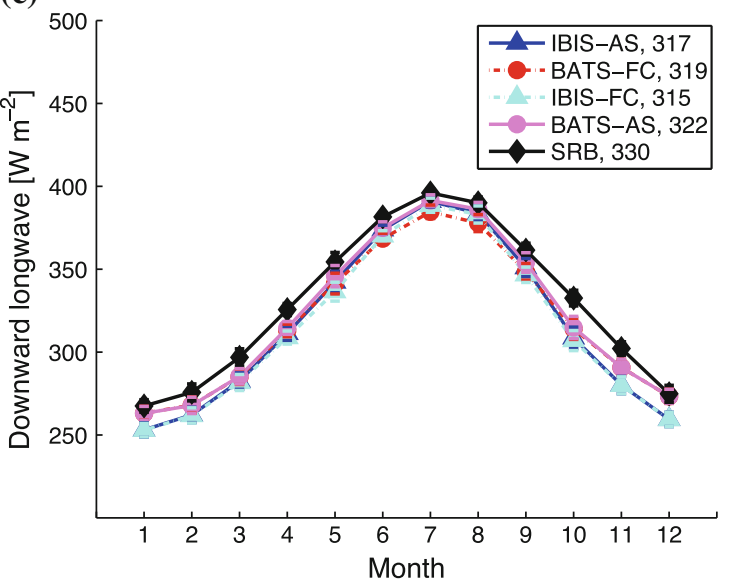

(e)

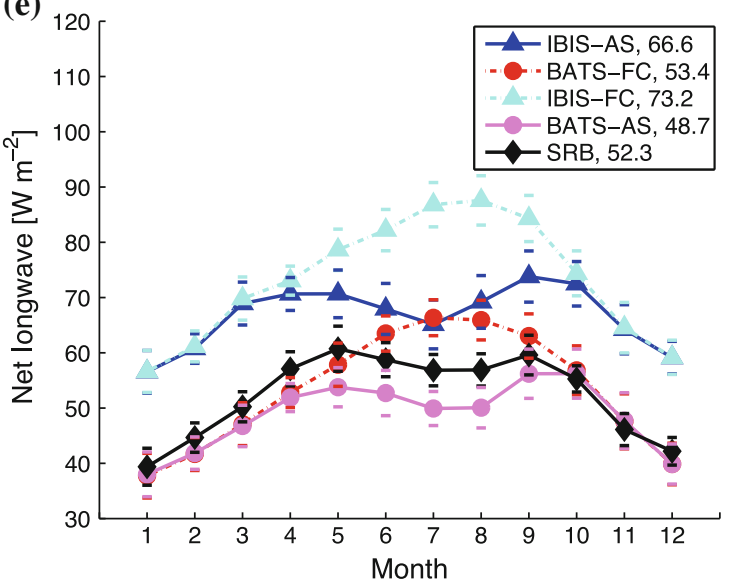

Fig. 3 NNRP2 control and observed seasonal cycles of: a two-meter air temperature, c downward longwave radiation, e net longwave radiation (defined as positive upward); and the difference between NNRP2 control and observed seasonal cycles of: b two-meter air temperature, d downward longwave radiation, $\mathbf{f}$ net longwave

by Diffenbaugh et al. (2006). BATS-AS simulates downward longwave radiation most accurately. BATS-FC underestimates summer downward longwave radiation by
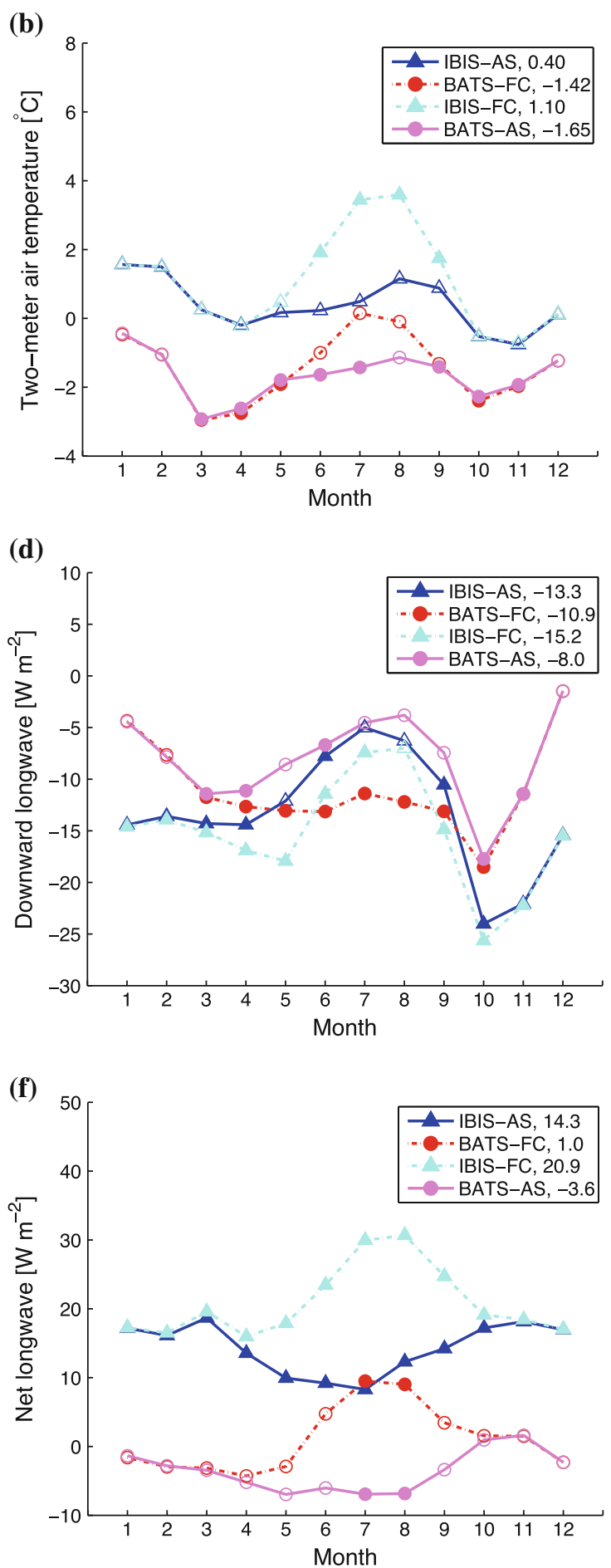

radiation (defined as positive upward) for 1984-2004 (two-meter air temperature 1984-2005). Error bars showing 95\% confidence intervals are included in panels (a, $\mathbf{c}, \mathbf{e})$, filled markers denote nonoverlapping confidence intervals in panels (b, d, f), and annual averages for each variable examined are provided in the legend

$12 \mathrm{~W} \mathrm{~m}^{-2}$, while IBIS-AS and IBIS-FC both underestimate winter downward longwave radiation by approximately $14 \mathrm{~W} \mathrm{~m}^{-2}$. BATS-FC simulates the annual average 
(a)

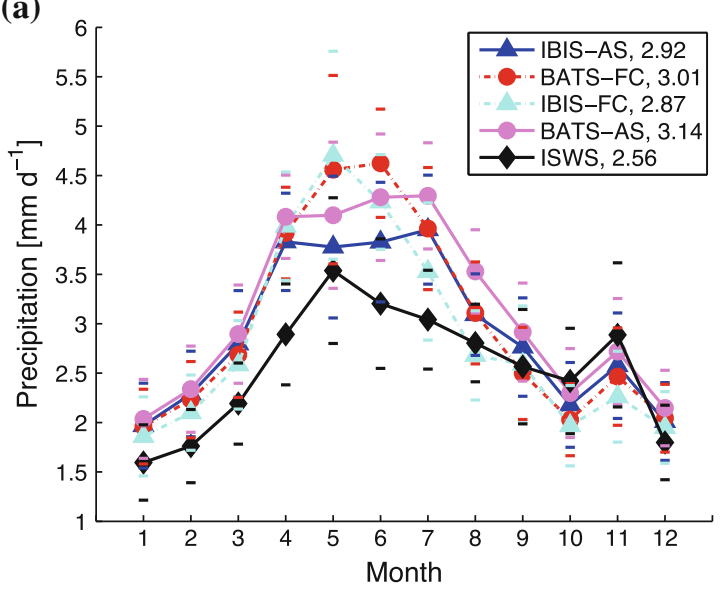

(c)

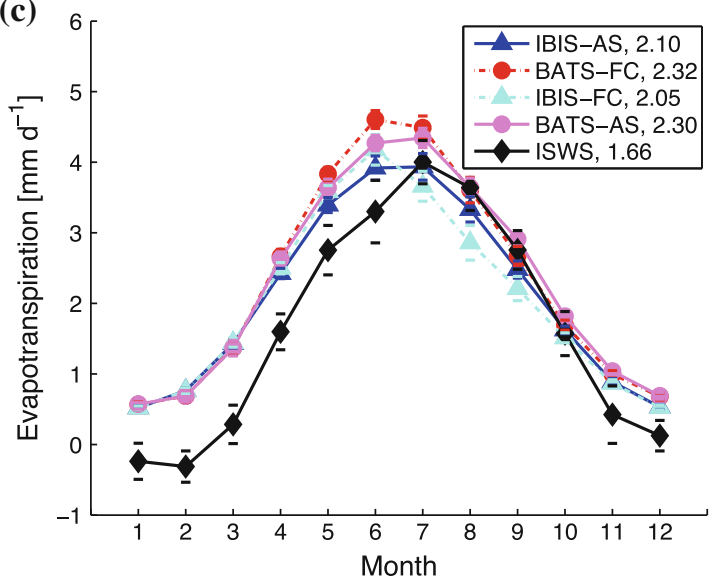

Fig. 4 NNRP2 control and observed seasonal cycles of: a precipitation, c evapotranspiration; and the difference between NNRP2 control and observed seasonal cycles of: b precipitation, d evapotranspiration for 1984-2005. Error bars showing 95\% confidence

of net longwave radiation (defined as positive upward) best; however, the shape of the seasonal cycle does not match observations. While BATS-AS is able to capture the shape of the net longwave radiation seasonal cycle, it underestimates net longwave radiation in July and August. IBIS-AS is also able to capture the shape of the net longwave radiation seasonal cycle; however, it consistently overestimates net longwave radiation by $\approx 14 \mathrm{~W} \mathrm{~m}^{-2}$ throughout the year. Net longwave radiation is influenced by convective closure via two-meter air temperature. FC80 allows considerably more incident shortwave radiation to reach the surface during the summer, which warms the ground and increases net longwave radiation.

For most months and model configurations, the 95\% confidence intervals of simulated and observed precipitation monthly means overlap (Fig. 4). However, precipitation is overestimated by all models during the spring and summer. IBIS-AS overestimates rainfall by $0.6 \mathrm{~mm}_{\text {day }}{ }^{-1}$ on average during the summer months. For those same
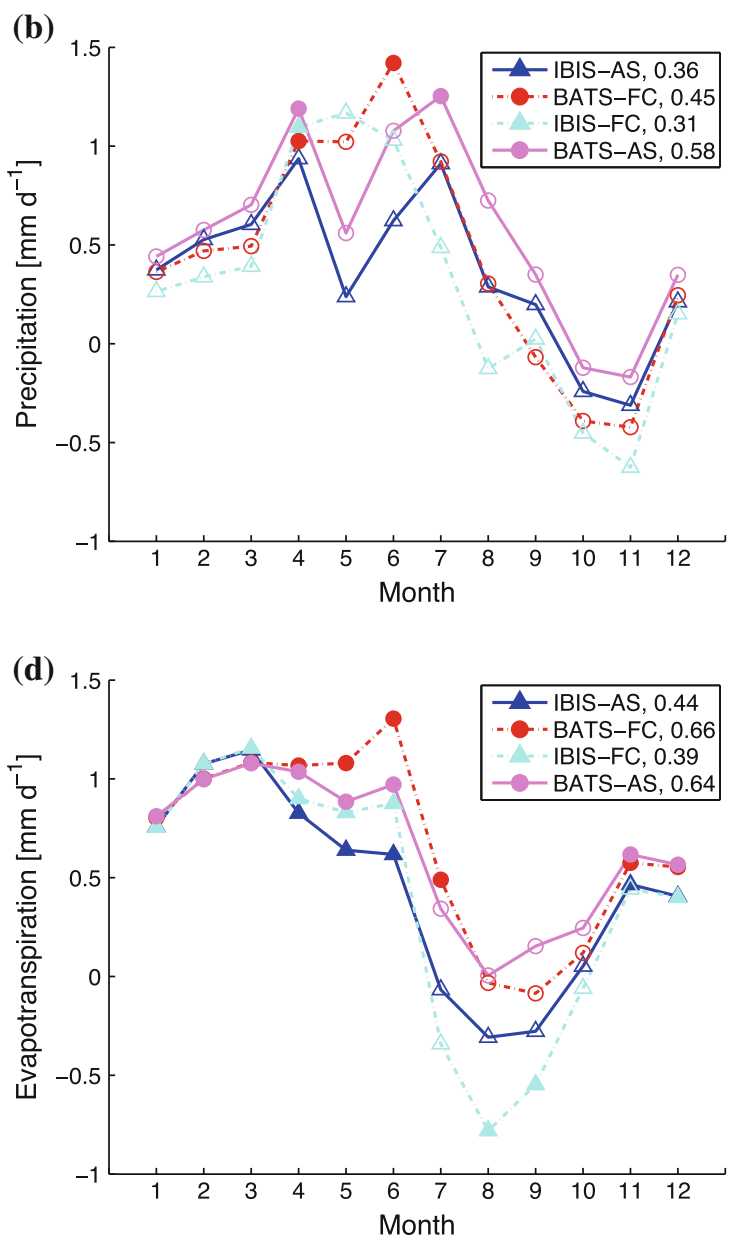

intervals are included in panels $(\mathbf{a}, \mathbf{c})$, filled markers denote nonoverlapping confidence intervals in panels $(\mathbf{b}, \mathbf{d})$, and annual averages for each variable examined are provided in the legend

months, the average wet bias in BATS-FC is $0.9 \mathrm{~mm}$ $\mathrm{day}^{-1}$. Errors in simulating precipitation are within the range of errors found in previous studies, including Diffenbaugh et al. (2006) and Liang et al. (2004). Difficulty in modeling precipitation is a key uncertainty of this study, and the large interannual variability of precipitation makes the assessment of simulated precipitation challenging. The seasonal cycle of evapotranspiration that is most consistent with observations is IBIS-AS; however, all models overestimate evapotranspiration in the winter and spring. Evapotranspiration is influenced primarily by surface physics scheme, but the overestimation of evapotranspiration is also a result of spring and summer wet biases in IBIS-AS, BATS-FC, IBIS-FC, and BATS-AS.

Total runoff is well simulated by IBIS-AS, BATS-FC, and BATS-AS, as shown in Fig. 5. IBIS-FC contains a large spike in precipitation that contributes to an average total runoff overestimation of $0.79 \mathrm{~mm}_{\text {day }}{ }^{-1}$ during May and June. Surface runoff is a function of both precipitation 

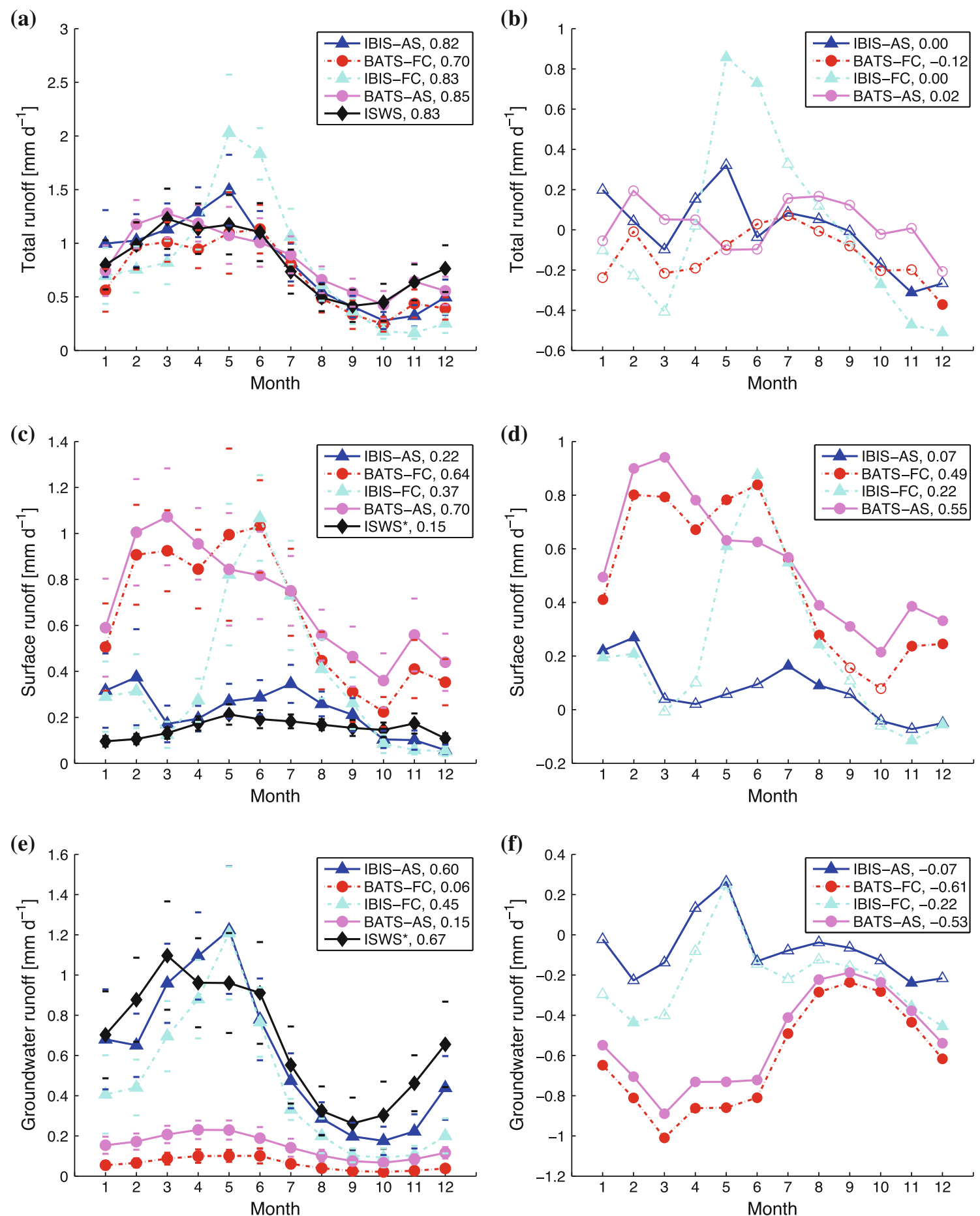

Fig. 5 NNRP2 control and observed seasonal cycles of: a total runoff, c surface runoff, e groundwater runoff; and the difference between NNRP2 control and observed seasonal cycles of: b total runoff, d surface runoff, f groundwater runoff for 1984-2005. Annual averages for each variable examined are provided in the legend. Error

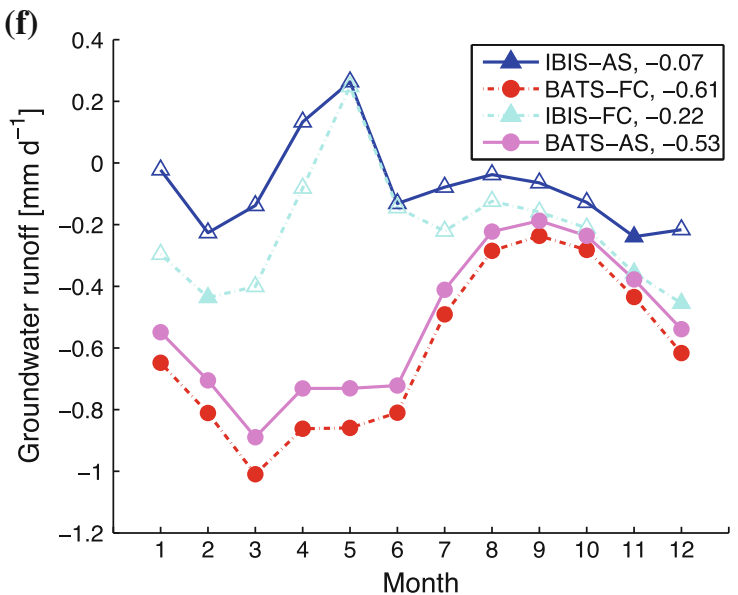

bars showing 95\% confidence intervals are included in panels (a, c, e), filled markers denote non-overlapping confidence intervals in panels $(\mathbf{b}, \mathbf{d}, \mathbf{f})$, and annual averages for each variable examined are provided in the legend. *estimate of runoff as described in Sect. 3

and surface physics scheme. IBIS-AS simulates surface runoff best. BATS-AS overestimates surface runoff throughout the year. This is a result of the inaccurate representation of surface and subsurface hydrology in

RegCM3-BATS1e. Groundwater runoff is poorly simulated by BATS-FC and BATS-AS. Annually averaged, both models produce less than a quarter of observed runoff. Values for groundwater runoff in IBIS-AS generally agree 
(a)

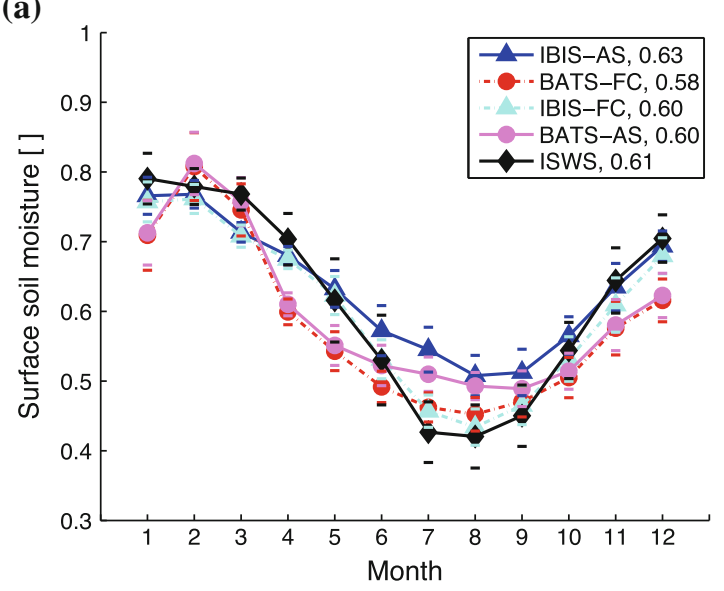

(c)

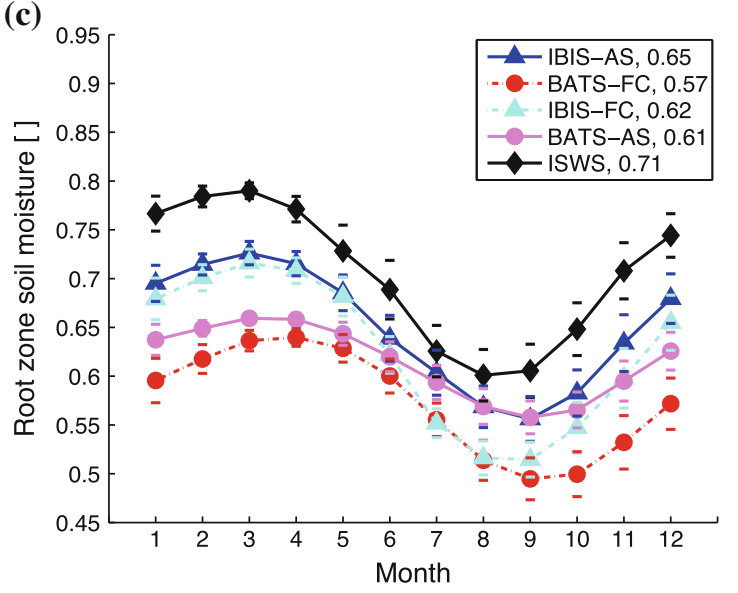

Fig. 6 NNRP2 control and observed seasonal cycles of: a surface soil moisture $(0-10 \mathrm{~cm})$, c root zone soil moisture $(0-100 \mathrm{~cm})$; and the difference between NNRP2 control and observed seasonal cycles of: b surface soil moisture $(0-10 \mathrm{~cm})$, d root zone soil moisture $(0-100$ $\mathrm{cm}$ ) for 1984-2003. Annual averages for each variable examined are

with observations; however, too little groundwater runoff is simulated during November, which is reflected in an underestimation of total runoff in those months.

BATS-FC and IBIS-FC simulate surface soil moisture more accurately during July and August than IBIS-AS and BATS-AS (Fig. 6). IBIS-AS overestimates surface soil moisture in July and August by 0.10 on average. The minimum of the seasonal cycle for root zone soil moisture is delayed one month in IBIS-AS, BATS-FC, and BATS-AS. While IBIS-FC does simulate the shape of the seasonal cycle of root zone soil moisture best, it is too dry throughout the year. Averaged annually, IBIS-AS and BATS-FC underestimate root zone soil moisture by 0.06 and 0.13 , respectively.

Figure 7 reveals the performance of IBIS-AS, BATSFC, IBIS-FC, and BATS-AS on a monthly basis. This yields important information about the variability of the climate system, as well as each model's skill in capturing that variability.
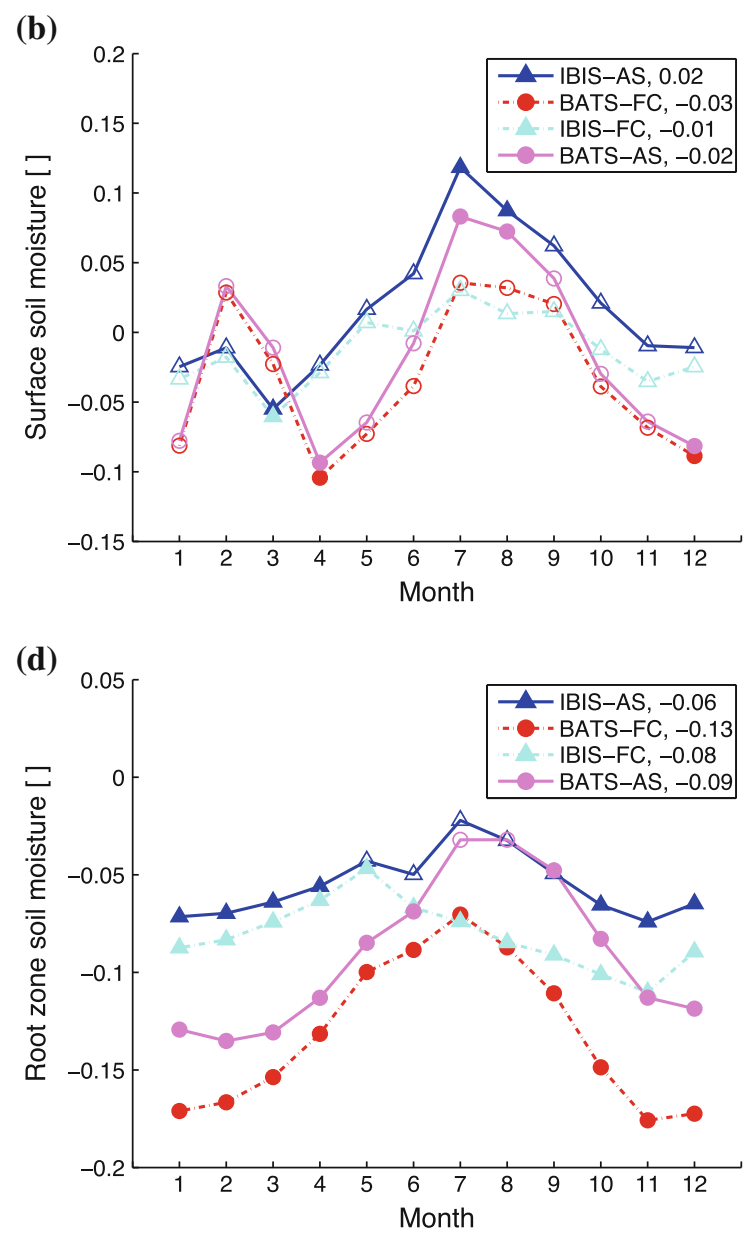

provided in the legend. Error bars showing 95\% confidence intervals are included in panels $(\mathbf{a}, \mathbf{c})$, filled markers denote non-overlapping confidence intervals in panels (b, d), and annual averages for each variable examined are provided in the legend

All models simulate two-meter air temperature well, with biases as noted in the legend. The overestimation of precipitation found in the seasonal cycle of each model is shown in Fig. 7. The large scatter indicates that the ability of IBIS-AS, BATS-FC, IBIS-FC, and BATS-AS to simulate the observed precipitation of any particular month is limited. All models also overestimate evapotranspiration; however, the correlations between simulated and observed evapotranspiration are higher than the correlations between simulated and observed precipitation. Note that negative values for observed evapotranspiration are artifacts of the surface and atmospheric water balance as described in Sect. 3. Surface runoff is simulated poorest of all variables examined when assessed using the correlation coefficient. IBIS-AS simulates groundwater runoff reasonably well; however, there is still considerable scatter in the data. Root zone soil moisture is clearly underestimated by IBIS-AS and IBIS-FC, but both models simulate root zone soil moisture better than BATS-FC and BATS-AS. 

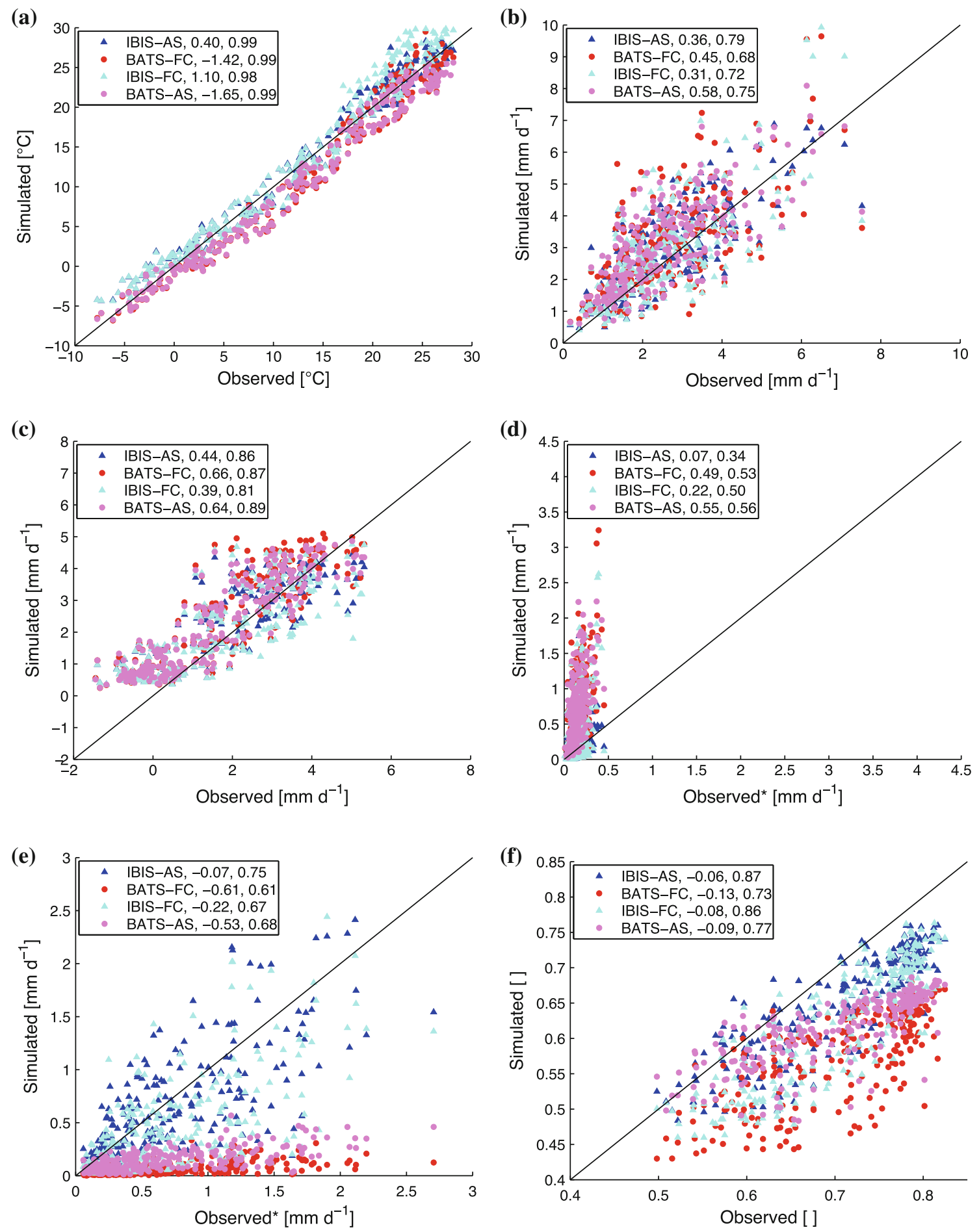

Fig. 7 Scatter plots of: a two-meter air temperature, b precipitation, $\mathbf{c}$ evapotranspiration, $\mathbf{d}$ surface runoff, e groundwater runoff, $\mathbf{f}$ root zone soil moisture $(0-100 \mathrm{~cm})$ using NNRP2 boundary conditions. Each point

The performance of IBIS-AS and BATS-FC across the contiguous United States during the summer (June, July, August) is shown in Fig. 8. IBIS-AS overestimates summer two-meter air temperature throughout much of the United States. This warm bias is especially pronounced along the

is a monthly average for 1984-2005 (root zone soil moisture 1984-2003). Biases and correlation coefficients for each variable examined are provided in the legend. *estimate of runoff as described in Sect. 3

west coast of California and the Baja Peninsula. BATS-AS also overestimates summer two-meter air temperatures along the west coast of California and the Baja Peninsula, but simulates a cold bias over the northwestern and southeastern United States. Summer precipitation is 
(a)

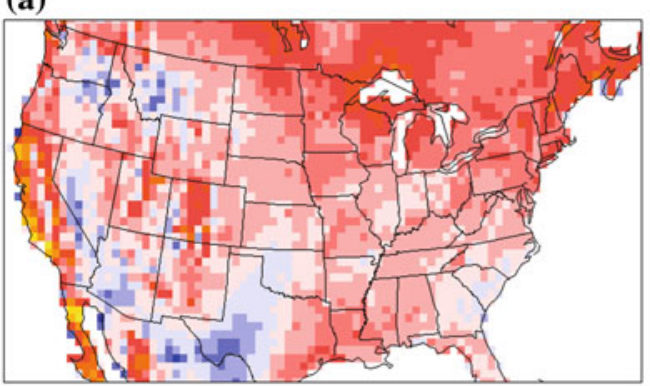

(c)

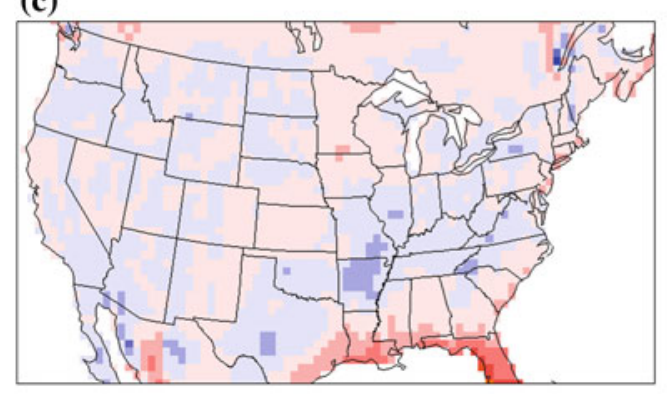

(b)

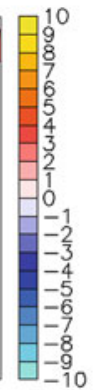

.

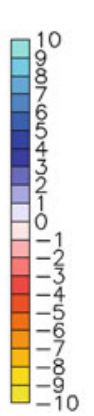

(d)
Fig. 8 Summer (June, July, August) bias for: a IBIS-AS two-meter air temperature $\left({ }^{\circ} \mathrm{C}\right)$, b BATS-FC two-meter air temperature $\left({ }^{\circ} \mathrm{C}\right)$, c IBIS-AS precipitation $\left(\mathrm{mm} \mathrm{d}^{-1}\right), \mathbf{d}$ BATS-FC precipitation $\left(\mathrm{mm} \mathrm{d}^{-1}\right)$

reasonably well modeled by IBIS-AS with the exception of an underestimation over the Gulf of Mexico coast and Florida. BATS-FC produces a wet bias across the majority of the United States, with the largest overestimations of summer precipitation in the southeastern United States and northern Mexico. In similar experiments, Diffenbaugh et al. (2006) found a warm bias across Oklahoma and northern Texas, and a wet bias in the upper Midwest. Liang et al. (2004) simulated precipitation over the United States using the fifth-generation Pennsylvania State UniversityNCAR Mesoscale Model, and noted a dry bias in the summertime precipitation of the Southeast.

\subsection{ECHAM5 GCM}

One model configuration using IBIS (IBIS-AS) and one model configuration using BATS1e (BATS-FC) were forced with boundary conditions derived from the EH5OM twentieth century (1984-2000) and EH5OM A1B (2001-2005) simulations to explore the influence of boundary conditions on energy and water fluxes. Model configurations were chosen based on their ability to reproduce the observed summer averages of key variables, specifically two-meter air temperature, precipitation, evapotranspiration, total runoff, and root zone soil moisture. As noted in Sect. 3, boundary conditions are continuous. The EH5OM model output for the domain examined is included for reference.

Figures 9, 10, 11, 12, and 13 present each variable using a pair of panels, where the left panel shows the EH5OM
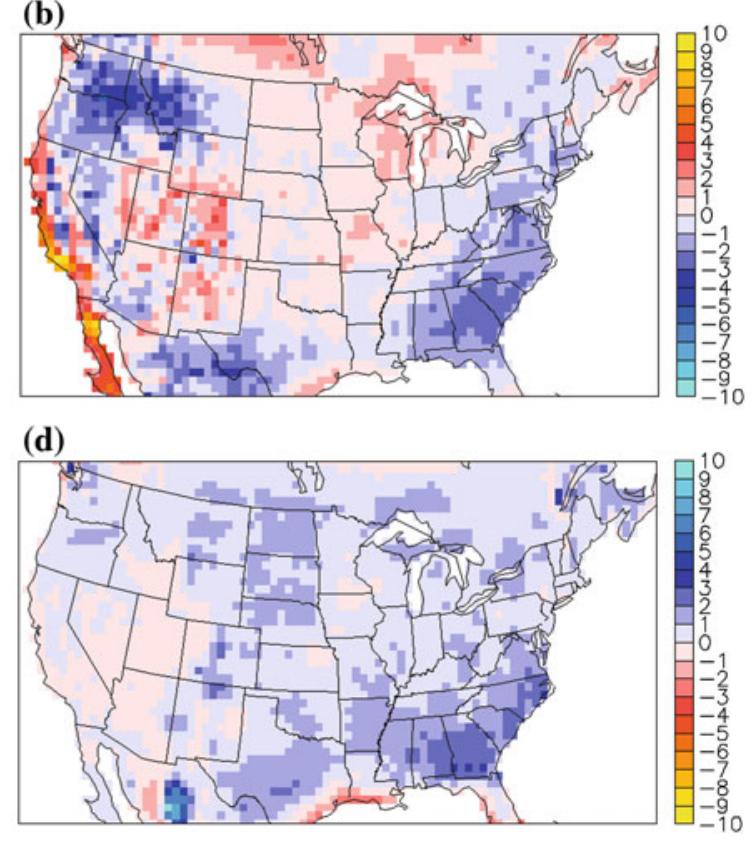

using NNRP2 boundary conditions. Each figure contains the difference between NNRP2 control and observed (CRU TS2.1) values for 1984-2002

control and observed seasonal cycles, and the right panel shows the difference between the EH5OM control and observed seasonal cycles. Error bars showing 95\% confidence intervals calculated using the Student's t-distribution are included in seasonal cycle figures, and filled markers in difference figures denote simulated and observed confidence intervals that do not overlap.

BATS-FC simulates incident surface shortwave radiation better during the summer when forced using EH5OM boundary conditions (Fig. 9); however, this improvement is likely a result of compensating errors. Inaccuracies in absorbed surface shortwave radiation are well correlated with incident surface shortwave radiation errors, suggesting a consistent surface albedo across models and observations. The ability of both IBIS-AS and BATS-FC to correctly simulate the shortwave radiation budget is consistent with their seasonal cycles of cloud cover, shown in Fig. 9. Incident top of atmosphere shortwave radiation is well simulated by IBIS-AS, BATS-FC, and EH5OM, and is included for completeness.

EH5OM provides cooler boundary conditions than NNRP2. As a result, IBIS-AS simulates two-meter air temperature correctly throughout most of the year, but underestimates August and October two-meter air temperature slightly (Fig. 10). BATS-FC develops a larger cold bias, and produces two-meter air temperatures that are consistently $\approx 2.3^{\circ} \mathrm{C}$ lower than observations. However, errors in two-meter air temperature are comparable, or in some cases less than, those found in Diffenbaugh et al. (2006) and Liang et al. (2006). BATS-FC simulates net longwave radiation (defined as positive upward) 
(a)

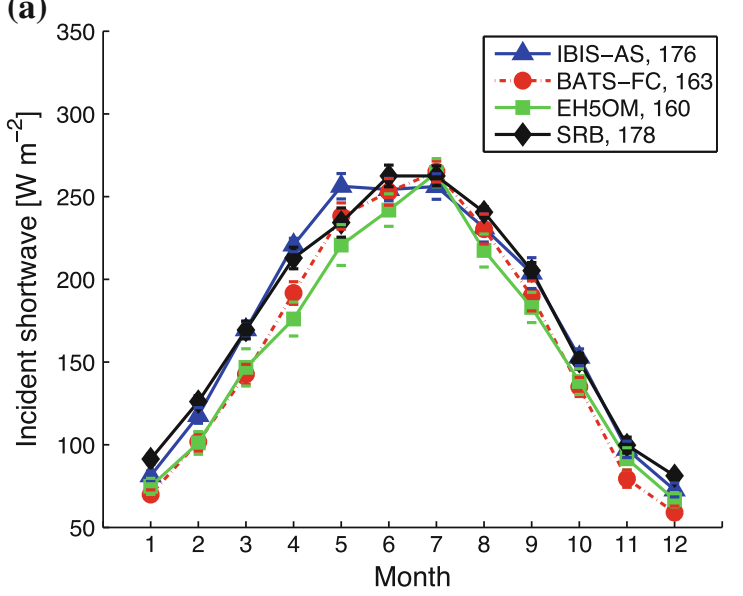

(c)

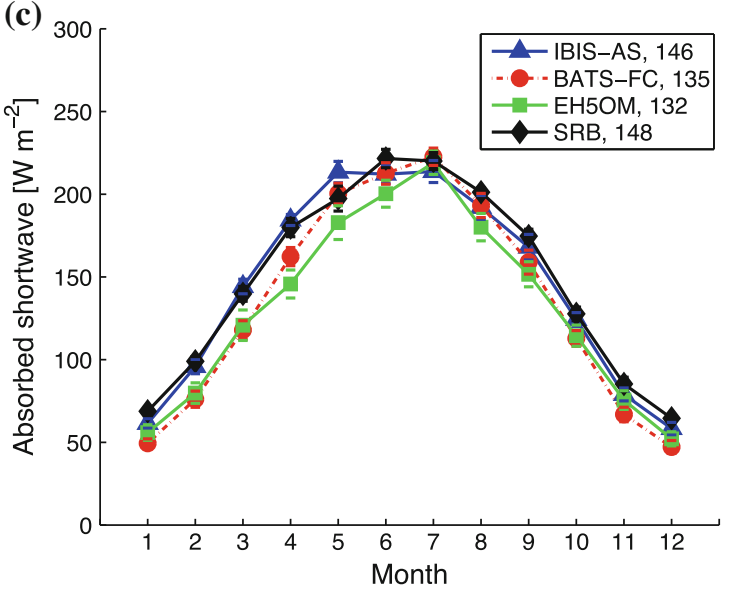

(e)

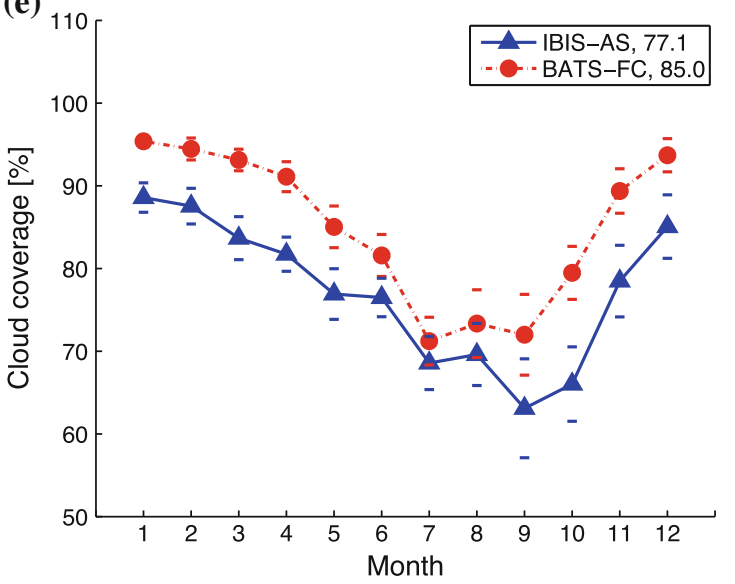

Fig. 9 EH5OM control and observed seasonal cycles of: a incident surface shortwave radiation, c absorbed surface shortwave radiation, e percentage of maximum model fractional cloud cover (0.8), f incident TOA shortwave radiation; and the difference between EH5OM control and observed seasonal cycles of: $\mathbf{b}$ incident surface

very well, benefitting from reduced surface temperatures during the months of June, July, and August (Fig. 10). This allows BATS-FC to capture both the correct magnitude and (b)
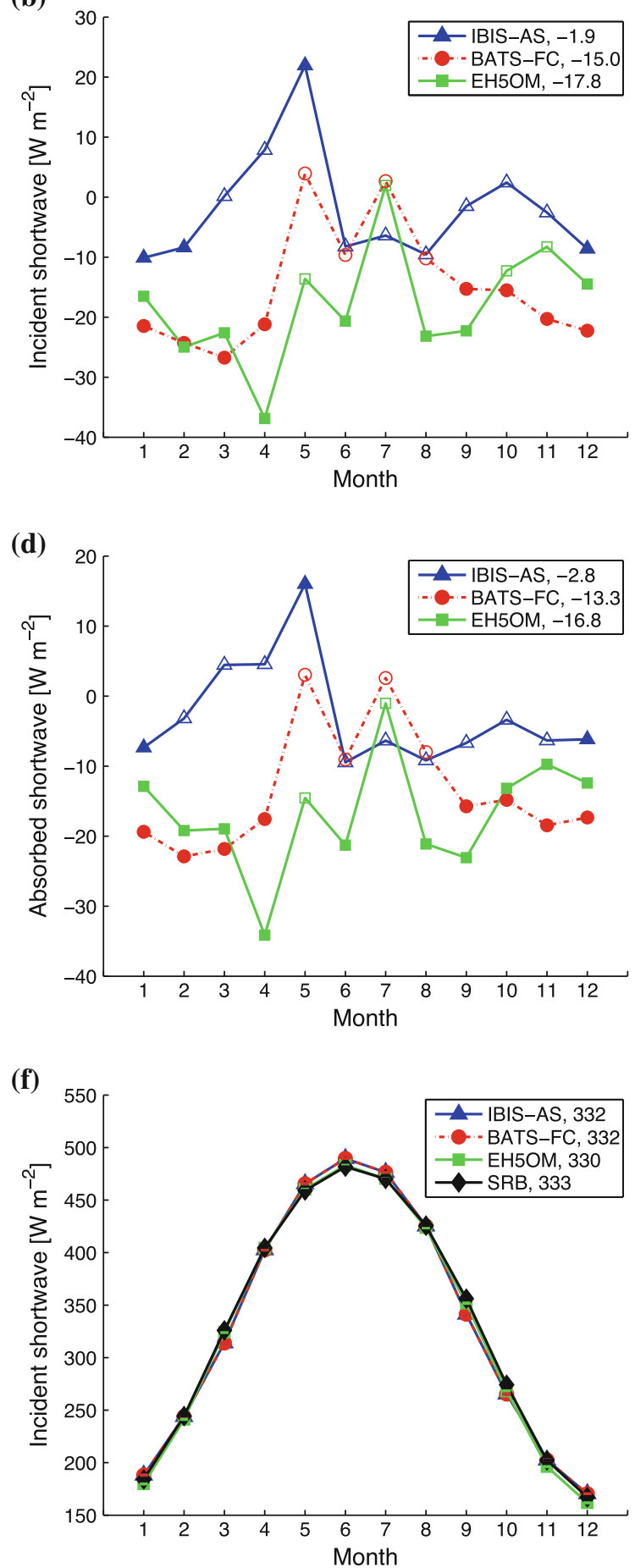

shortwave radiation, $\mathbf{d}$ absorbed surface shortwave radiation for 1984-2004. Error bars showing 95\% confidence intervals are included in panels (a, c, e, f), filled markers denote non-overlapping confidence intervals in panels (b, d), and annual averages for each variable examined are provided in the legend

shape of the observed seasonal cycle. It is expected that correcting the bias in downward longwave radiation in IBIS-AS would fix errors in net longwave radiation. 
(a)

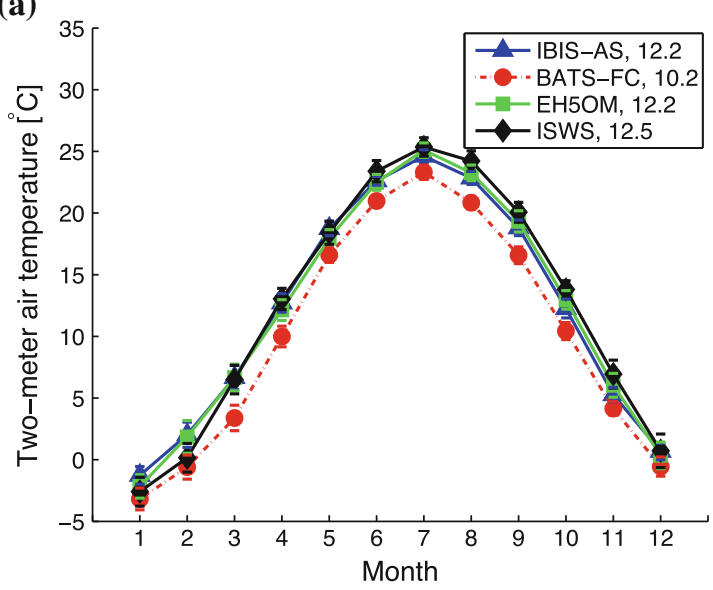

(c)

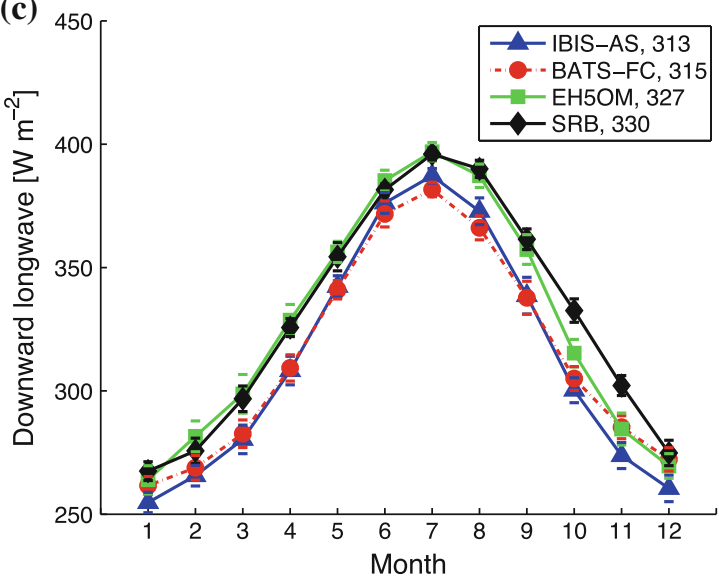

(e)

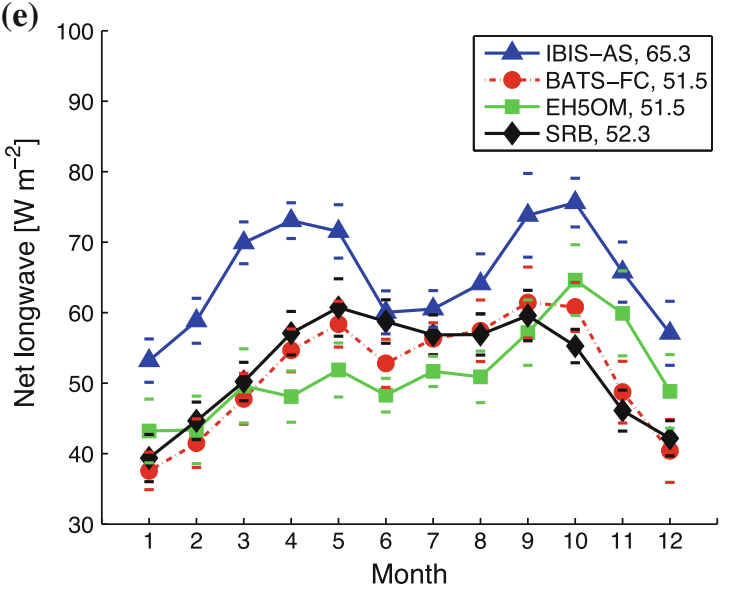

Fig. 10 EH5OM control and observed seasonal cycles of: a two-meter air temperature, c downward longwave radiation, e net longwave radiation (defined as positive upward); and the difference between EH5OM control and observed seasonal cycles of: b two-meter air temperature, $\mathbf{d}$ downward longwave radiation, $\mathbf{f}$ net longwave radiation

Precipitation is overestimated by all three models in June and July. IBIS-AS simulates a wet bias of $1.3 \mathrm{~mm}$ day $^{-1}$ during the summer, and BATS-FC overestimates
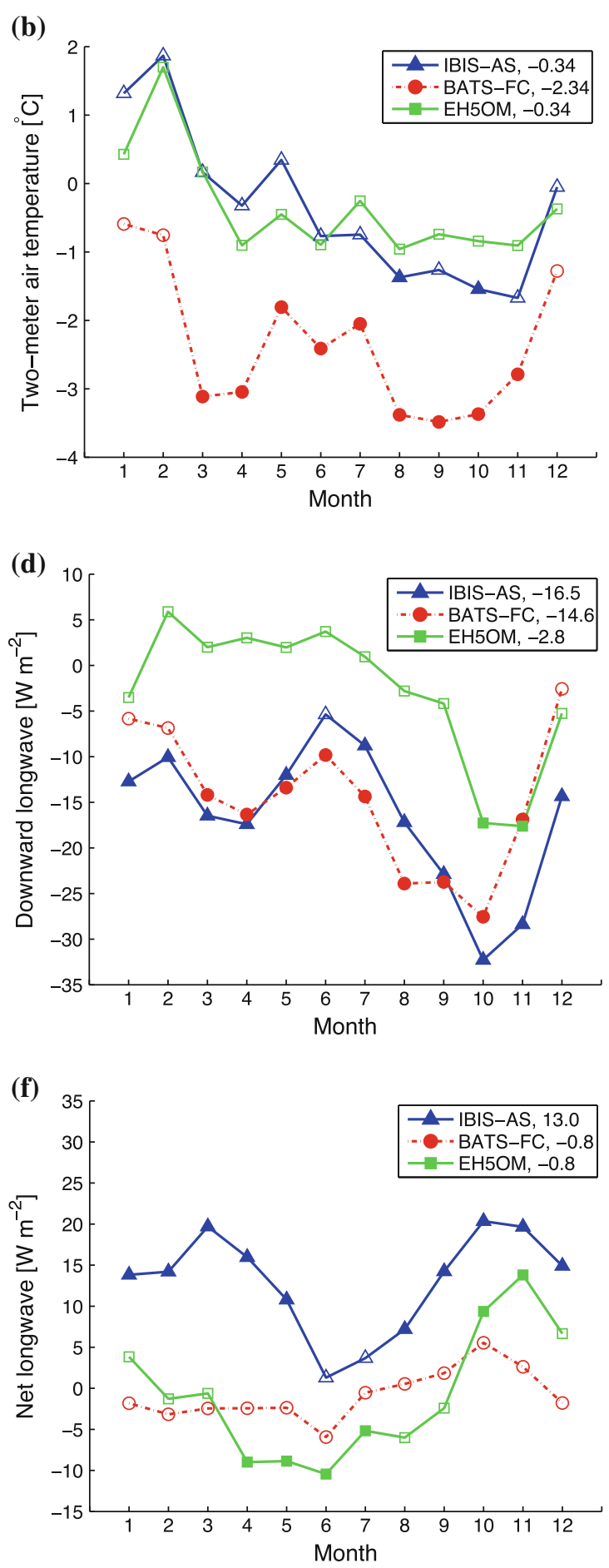

(defined as positive upward) for 1984-2004 (two-meter air temperature 1984-2005). Error bars showing 95\% confidence intervals are included in panels (a, c, e), filled markers denote non-overlapping confidence intervals in panels (b, d, f), and annual averages for each variable examined are provided in the legend

precipitation in June and July by $1.5 \mathrm{~mm} \mathrm{day}^{-1}$ on average. IBIS-AS and BATS-FC forced with EH5OM data simulate more rainfall than IBIS-AS and BATS-FC forced with 

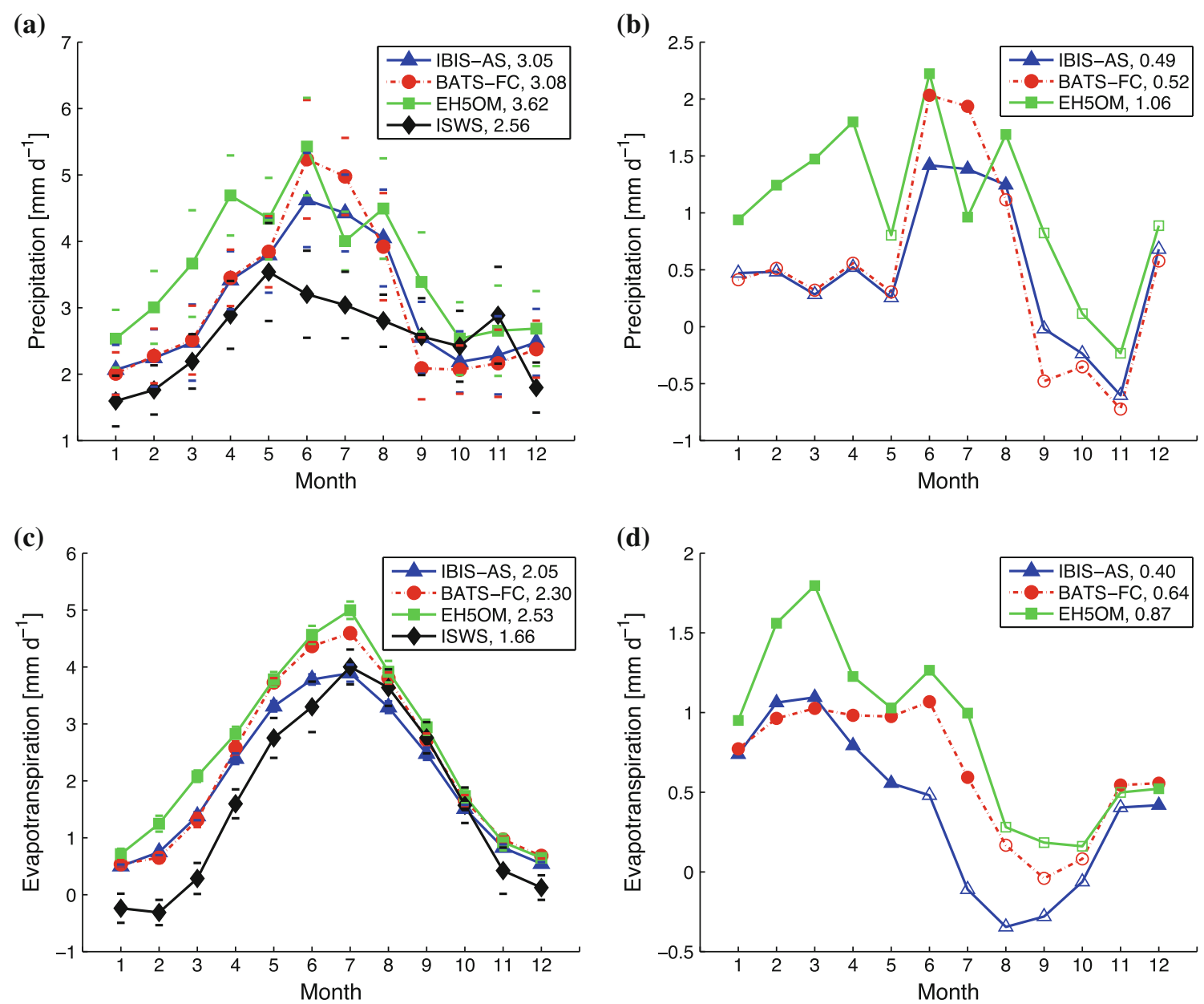

Fig. 11 EH5OM control and observed seasonal cycles of: a precipitation, c evapotranspiration; and the difference between EH5OM control and observed seasonal cycles of: b precipitation, d evapotranspiration for 1984-2005. Error bars showing 95\% confidence

NNRP2 data, suggesting wetter boundary conditions. This is consistent with the wet bias in the EH5OM simulation. The overestimation of precipitation seems largely independent of surface physics scheme and convective closure assumption. Biases in precipitation are similar to those found in previous experiments by Diffenbaugh et al. (2006) and Liang et al. (2006). Evapotranspiration is heavily influenced by surface physics scheme (Fig. 11), as changing boundary conditions from NNRP2 to EH5OM has a minimal effect on the IBIS-AS and BATS-FC evapotranspiration seasonal cycles.

Total runoff is reasonably well simulated by both regional climate models; however, IBIS-AS does overestimate total runoff during July and August by $0.46 \mathrm{~mm}$ day $^{-1}$ (Fig. 12). IBIS-AS and BATS-FC produce excess surface runoff during the summer, a result of both increased precipitation and errors in the representation of surface and subsurface hydrology. Groundwater runoff is well simulated by IBIS-AS, and the underestimation of

intervals are included in panels (a, c), filled markers denote nonoverlapping confidence intervals in panels $(\mathbf{b}, \mathbf{d})$, and annual averages for each variable examined are provided in the legend

groundwater runoff during the month of November present in the IBIS-AS simulation using NNRP2 boundary conditions has been eliminated, likely a result of compensating errors.

EH5OM parameterizes soil moisture using a modified "bucket model". Soil moisture in EH5OM is the amount of water in the bucket relative to the total volume of the bucket (field capacity of the soil). Because values for IBIS-AS and BATS-FC are given as fraction of total soil pore space containing liquid water, the soil moisture of EH5OM (which is relative to the soil field capacity) was scaled by the ratio of field capacity to total pore space derived from ISWS observations. Note that EH5OM simulates soil moisture as a singular bucket, so EH5OM values for surface and root zone soil moisture are the same. Surface soil moisture is overestimated by BATSFC in July and August, and IBIS-AS in late summer (July, August, September). Excess surface soil moisture in both models during July and August correlate with the 

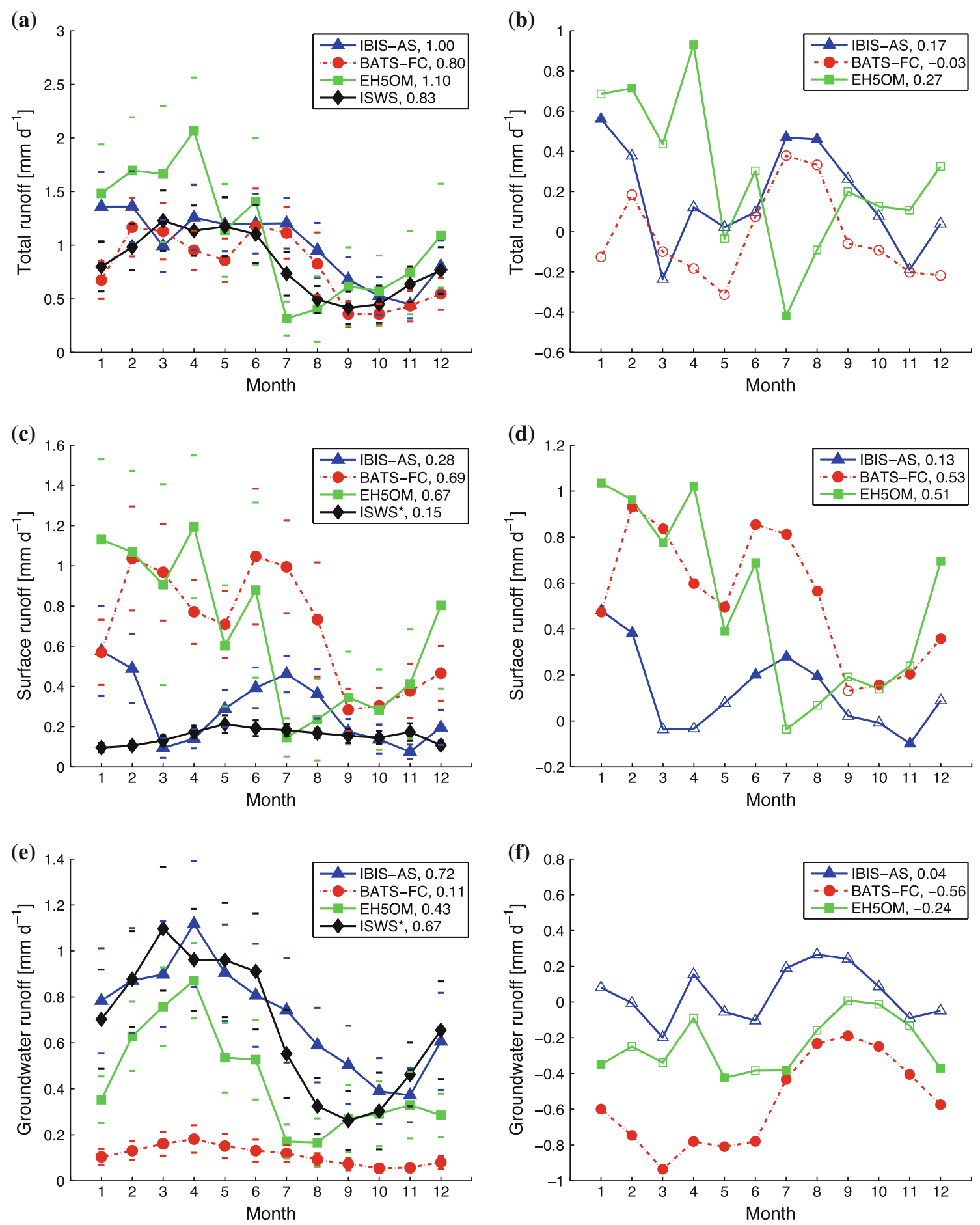

Fig. 12 EH5OM control and observed seasonal cycles of: a total runoff, c surface runoff, e groundwater runoff; and the difference between EH5OM control and observed seasonal cycles of: b total runoff, d surface runoff, f groundwater runoff for 1984-2005. Error

bars showing $95 \%$ confidence intervals are included in panels (a, c, e), filled markers denote non-overlapping confidence intervals in panels (b, d, f), and annual averages for each variable examined are provided in the legend. *estimate of runoff as described in Sect. 3

overestimation of summer precipitation in IBIS-AS and BATS-FC. IBIS-AS captures the seasonal cycle of root zone soil moisture best (Fig. 13). The dry bias in BATSFC root zone soil moisture is reduced by using EH5OM

boundary conditions instead of NNRP2 boundary conditions, especially during the July, August, and September. However, this improvement is likely a result of compensating errors. 


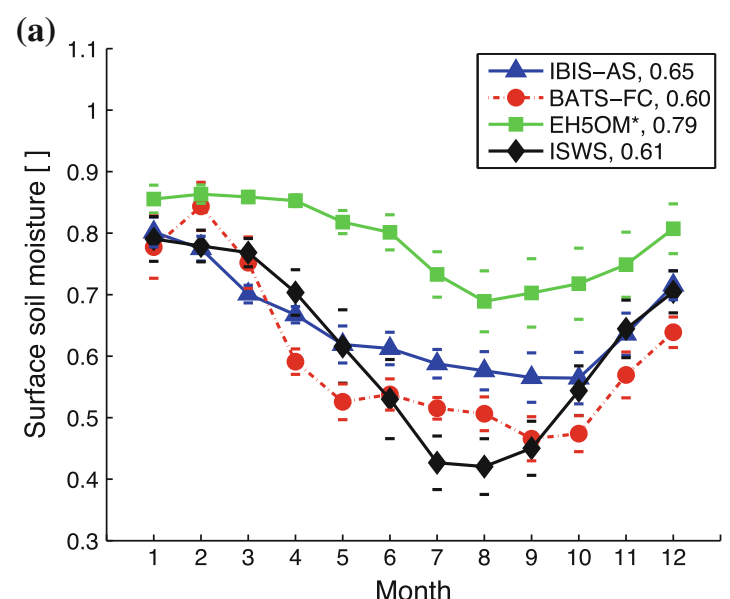

(c)

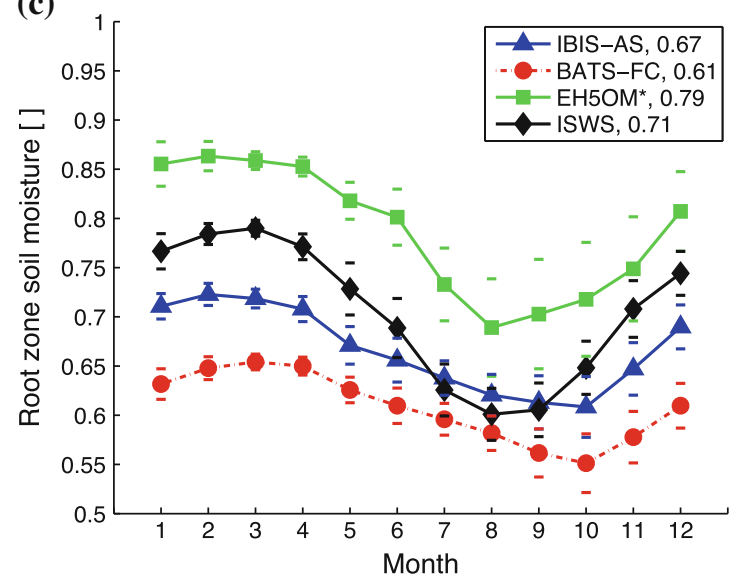

Fig. 13 EH5OM control and observed seasonal cycles of: a surface soil moisture $(0-10 \mathrm{~cm})$, c root zone soil moisture $(0-100 \mathrm{~cm})$; and the difference between EH5OM control and observed seasonal cycles of: b surface soil moisture $(0-10 \mathrm{~cm}), \mathbf{d}$ root zone soil moisture $(0-100 \mathrm{~cm})$

Figure 14 reveals the performance of IBIS-AS and BATS-FC on a monthly basis. This yields important information about the variability of the climate system, as well as each model's skill in capturing that variability.

Changing boundary conditions from NNRP2 to EH5OM decreases the correlation between simulated and observed two-meter air temperature in IBIS-AS and BATS-FC. This increased scatter in both models indicates a reduced ability of IBIS-AS and BATS-FC to correctly model two-meter air temperature. The simulation of precipitation in IBIS-AS and BATS-FC is also degraded, including higher extreme values and larger biases, when EH5OM boundary conditions are used instead of NNRP2 boundary conditions. However, the bias and correlation of IBIS-AS and BATSFC show that both RCMs improve the simulation of precipitation relative to EH5OM. Simulated values of evapotranspiration shown in Fig. 14 appear relatively unchanged from the NNRP2 experiments, suggesting that evapotranspiration is strongly controlled by surface physics
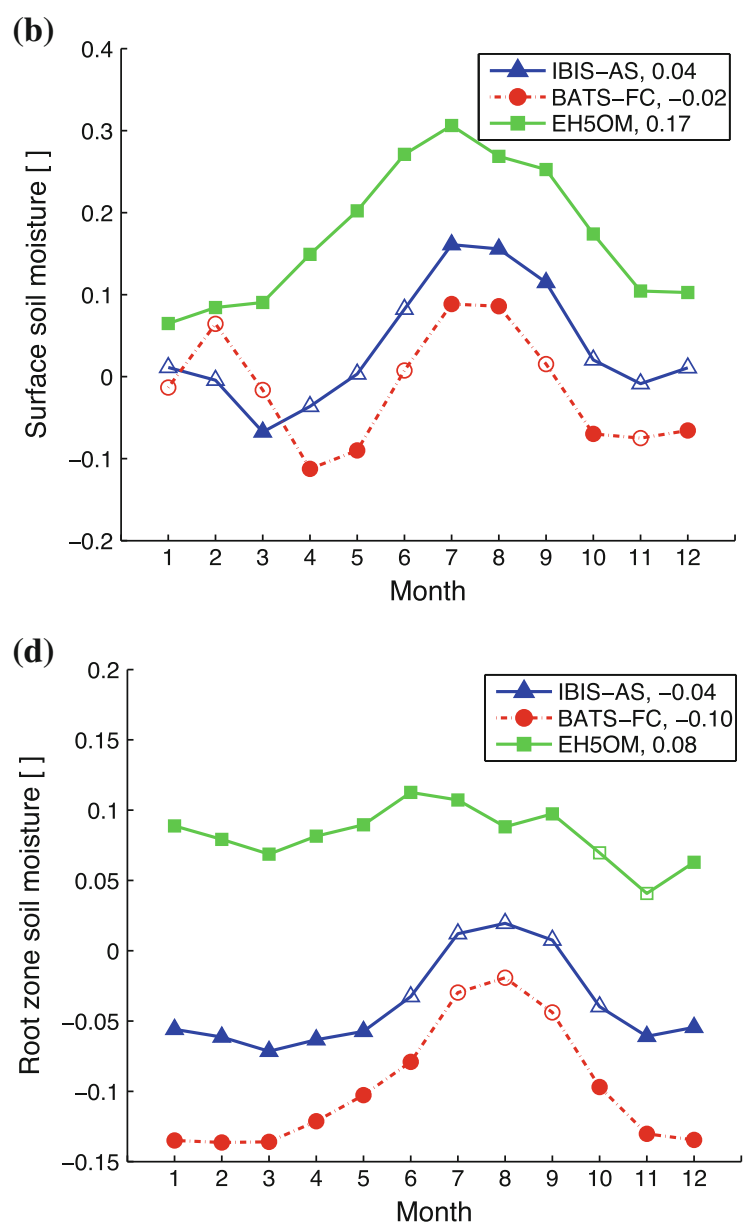

for 1984-2003. Error bars showing 95\% confidence intervals are included in panels $(\mathbf{a}, \mathbf{c})$, filled markers denote non-overlapping confidence intervals in panels (b, d), and annual averages for each variable examined are provided in the legend. *estimate of soil moisture as described in Sect. 4.2

scheme and relatively unresponsive to changes in boundary conditions. Note that negative values for observed evapotranspiration are artifacts of the surface and atmospheric water balance as described in Sect. 3. IBIS-AS and BATSFC both model surface runoff very poorly on a monthly basis, and correlations between groundwater runoff simulated by IBIS-AS and BATS-FC using EH5OM boundary conditions and observed groundwater runoff are lower than correlations between groundwater runoff simulated by IBIS-AS and BATS-FC using NNRP2 boundary conditions and observed groundwater runoff. The ability of IBIS-AS and BATS-FC to simulate monthly root zone soil moisture is diminished by using EH5OM boundary conditions instead of NNRP2 boundary conditions.

The performance of IBIS-AS and BATS-FC throughout the contiguous United States during the summer (June, July, August) is shown in Fig. 15. The summer two-meter air temperature bias of IBIS-AS using EH5OM boundary conditions is smaller than the summer two-meter air 
(a)

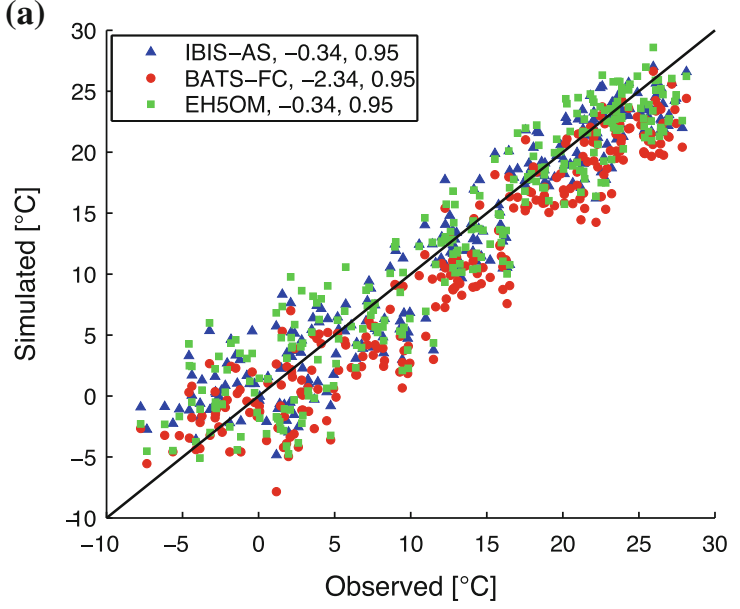

(c)

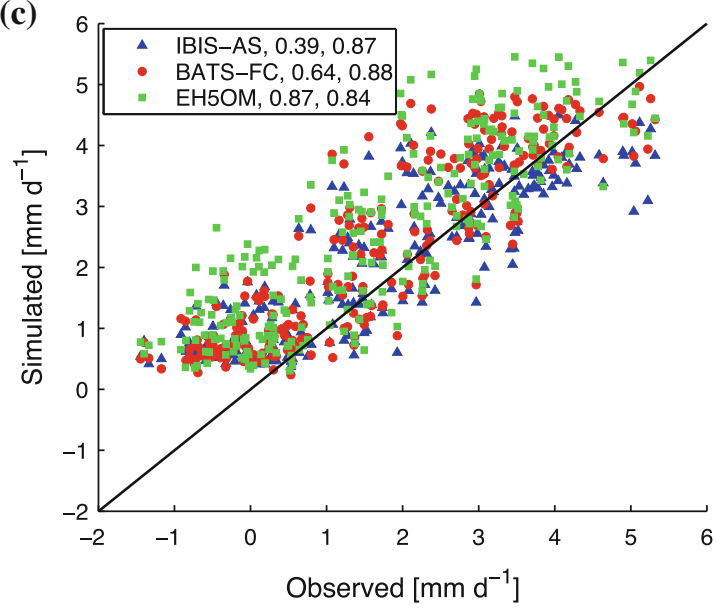

(e)

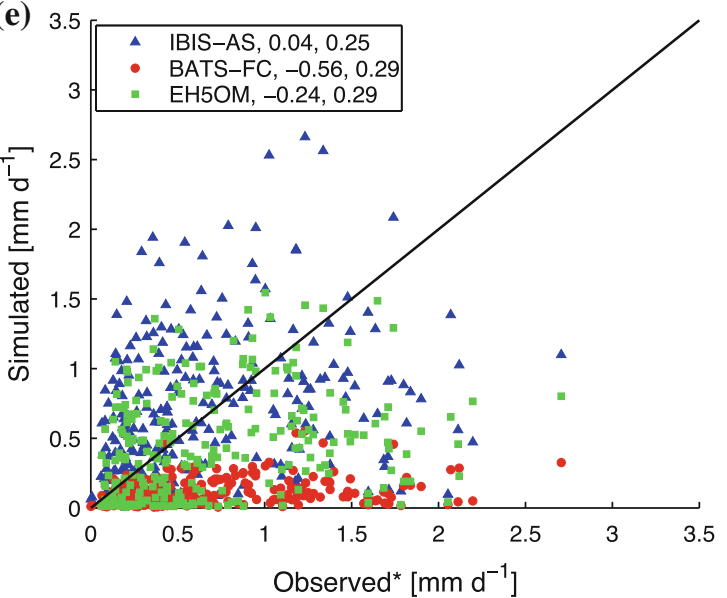

Fig. 14 Scatter plots of: a two-meter air temperature, b precipitation, $\mathbf{c}$ evapotranspiration, $\mathbf{d}$ surface runoff, $\mathbf{e}$ groundwater runoff, $\mathbf{f}$ root zone soil moisture $(0-100 \mathrm{~cm})$ using EH5OM boundary conditions. Each point

temperature bias of IBIS-AS using NNRP2 boundary conditions across the eastern half of the United States, likely a result of compensating errors. IBIS-AS simulates a
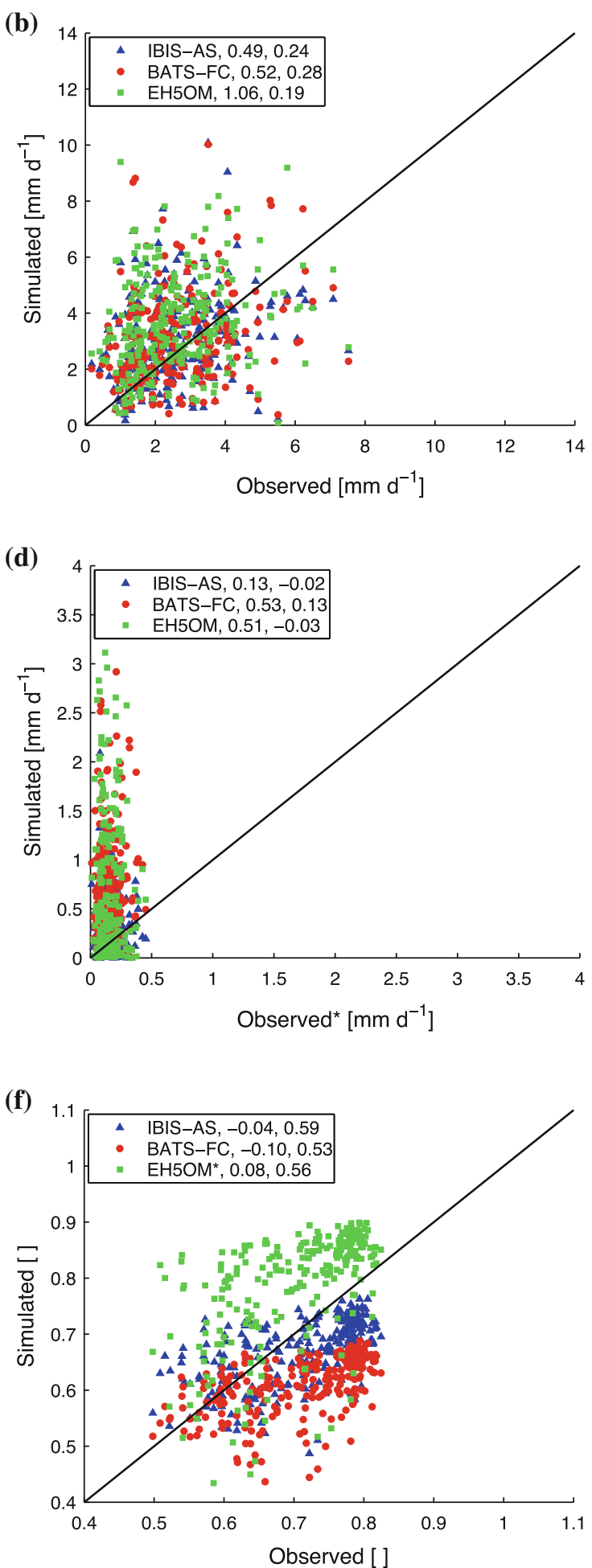

is a monthly average for 1984-2005 (root zone soil moisture 1984-2003). Biases and correlation coefficients for each variable examined are provided in the legend. *estimate of runoff as described in Sect. 3

pronounced warm bias over the west coast of California and the Baja Peninsula, as well as a cold bias in Montana and northern Mexico. BATS-FC forced by EH5OM shows 
(a)

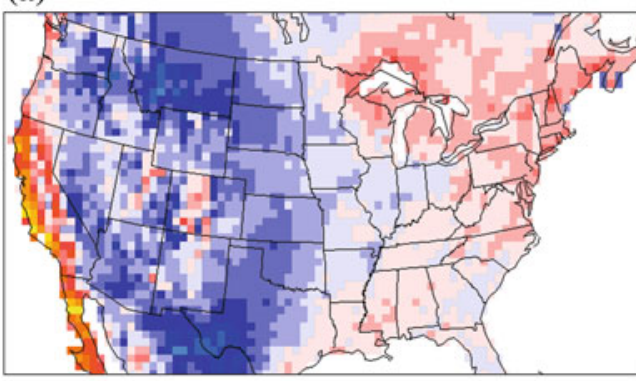

(c)

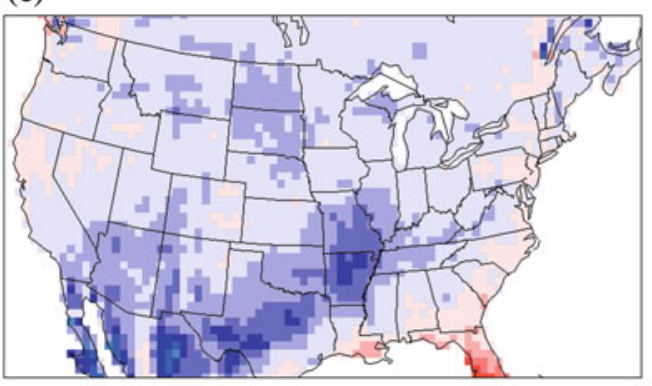

(b)
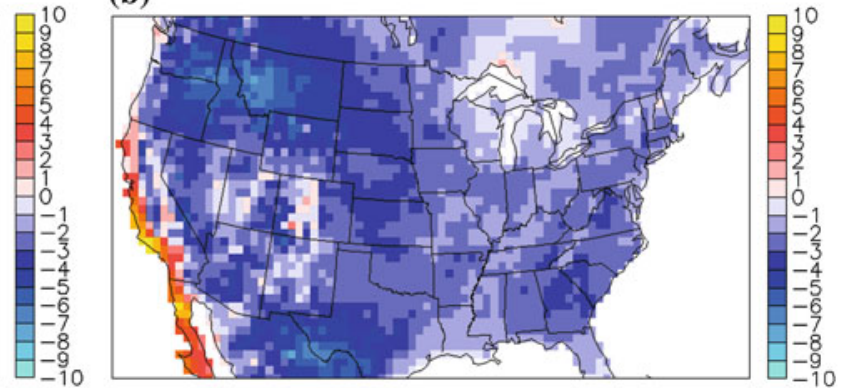

(d)
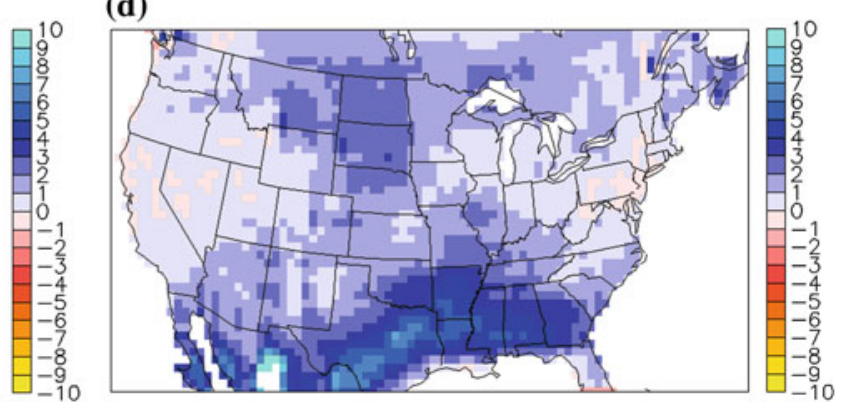

Fig. 15 Summer (June, July, August) bias for: a IBIS-AS two-meter air temperature $\left({ }^{\circ} \mathrm{C}\right)$, b BATS-FC two-meter air temperature $\left({ }^{\circ} \mathrm{C}\right)$, c IBIS-AS precipitation $\left(\mathrm{mm} \mathrm{d}^{-1}\right), \mathbf{d}$ BATS-FC precipitation $\left(\mathrm{mm} \mathrm{d}^{-1}\right)$ using EH5OM boundary conditions. Each figure contains the

reduced accuracy in capturing summer two-meter air temperatures relative to BATS-FC forced by NNRP2 boundary conditions. While BATS-FC does simulate a warm bias along the west coast of California, the rest of the domain is too cold when compared to CRU TS2.1, especially over Montana and northern Mexico. Consistent with Fig. 11, summer precipitation simulated by both IBIS-AS and BATS-FC increases throughout the United States when forced using EH5OM boundary conditions instead of NNRP2 boundary conditions. While the dry bias along the Gulf of Mexico coast and Florida in IBIS-AS is reduced, a series of wet biases are created across northern Mexico running up the Central Mississippi Valley. EH5OM boundary conditions enhance the summer wet bias simulated by BATS-FC using NNRP2 data, particularly across the southern United States. In experiments using RegCM3 forced with NCAR Community Climate System Model, Diffenbaugh et al. (2006) found a warm bias throughout the southeastern and central United States, a dry bias over the Southeast, and a wet bias over the Great Plains.

Figure 16 shows the seasonal cycles of all six numerical experiments conducted (ensemble members), as well as the ensemble mean and observations for key hydrologic variables. The ensemble mean overestimates precipitation during April, June, and July. Large interannual variability in precipitation makes model evaluation difficult, and disregarding error bars precipitation is overestimated throughout the year by the ensemble mean. The ensemble

difference between EH5OM control and observed (CRU TS2.1) values for 1984-2002. White pixels surrounded by intense color (e.g. central Mexico in the lower right panel) denote biases that are larger or smaller than the color bar limits

mean simulates too much evapotranspiration in all seasons except late summer and fall (September, October, November). Total runoff is well modeled by most ensemble members and the ensemble mean, whereas soil moisture is underestimated by the ensemble mean throughout the entire year.

\section{Summary and conclusions}

The performance of RegCM3-IBIS and RegCM3-BATS1e was comprehensively evaluated over the American Midwest. Temperature and precipitation, as well as the primary components of the shortwave radiation, longwave radiation, surface water, and subsurface water budgets, were examined. This paper describes one of the most extensive assessments of a regional climate model in the United States to date.

Overall, the model that reproduces the observed seasonal cycles of the climate system best using NNRP2 boundary conditions is IBIS-AS. IBIS-AS accurately simulates incident and absorbed surface shortwave radiation, while incident and absorbed surface shortwave radiation is underestimated by BATS-AS for most months and overestimated by BATS-FC and IBIS-FC during the summer. Values for net longwave radiation produced by BATS-FC and BATS-AS are in reasonable agreement with observations. IBIS-AS and IBIS-FC overestimate net longwave 

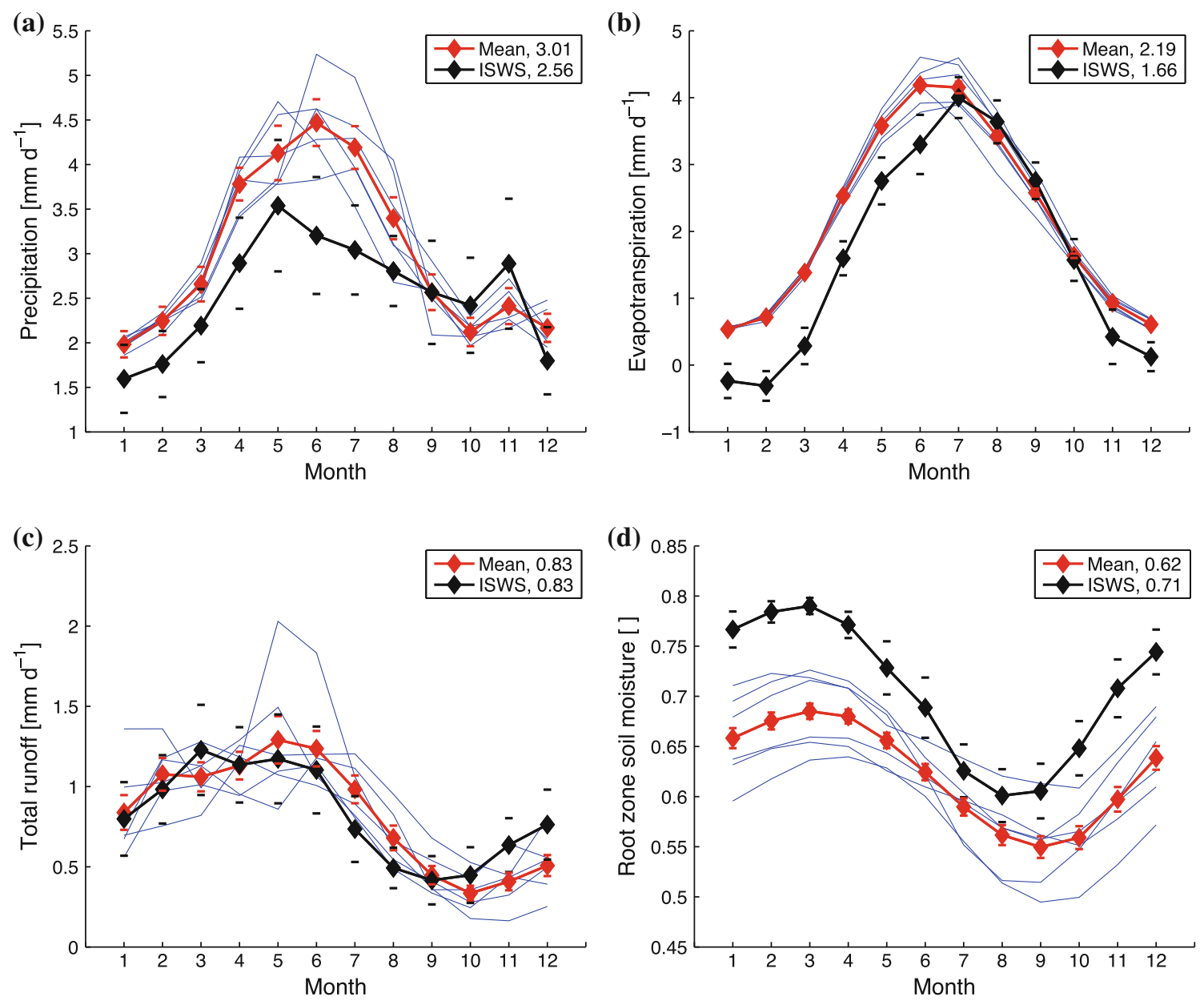

Fig. 16 Ensemble members, ensemble mean, and observed seasonal cycles of: a precipitation, $\mathbf{b}$ evapotranspiration, $\mathbf{c}$ total runoff, $\mathbf{d}$ root zone soil moisture $(0-100 \mathrm{~cm}$ ) for 1984-2005 (root zone soil

moisture 1984-2003). Error bars showing 95\% confidence intervals are included in panels (a, b, c, d) and annual averages for each variable examined are provided in the legend

IBIS-AS also performs best using EH5OM boundary radiation throughout the year. Two-meter air temperature is well simulated by IBIS-AS. BATS-AS is too cold on average, and IBIS-FC overestimates two-meter air temperature during the summer. IBIS-AS, BATS-FC, IBIS-FC, and BATS-AS simulate excess precipitation relative to observations in the spring, summer, and winter; however, the large interannual variability in modeled and measured precipitation make the significance of these differences difficult to evaluate. Evapotranspiration is overestimated by all models in the winter and spring. Total runoff and groundwater runoff are well simulated by IBIS-AS. While BATS-FC and BATS-AS do model the seasonal cycle of total runoff well, gross errors in the partitioning of total runoff between surface runoff and groundwater runoff exist. All models overestimate surface runoff. The seasonal cycle of root zone soil moisture simulated by IBIS-AS is slightly dry, but agrees well with observations from May through September. BATS-FC, IBIS-FC, and BATS-AS all underestimate root zone soil moisture. conditions. Increased cloud cover caused by the EH5OM forcing reduces shortwave radiation incident in BATS-FC, resulting in a cold bias during the summer. The overestimation of IBIS-AS and BATS-FC summer precipitation is larger in the EH5OM experiments than the overestimation of IBIS-AS and BATS-FC summer precipitation in the NNRP2 experiments.

The extent of differences between the six simulations conducted is highly dependent on the variable examined, and the assessment of these differences is a function of both the deviations among, as well as the interannual variability of, the seasonal cycles. In general, net longwave radiation, surface runoff, groundwater runoff, and root zone soil moisture are most sensitive to choice of model setup, whereas simulated values for total runoff and surface soil moisture are fairly consistent across experiments.

Convective closure assumption, surface physics scheme, and boundary conditions, which all impact cloudiness, 
influence the simulation of shortwave radiation. Two-meter air temperature is dependent primarily on surface physics scheme and boundary conditions; however, during the summer convective closure assumption may become important. The simulation of precipitation is most dependent on convective closure assumption and boundary conditions, while evapotranspiration, surface runoff, and groundwater runoff are strongly controlled by surface physics scheme. Surface physics scheme influences root zone soil moisture throughout the year, and during the summer root zone soil moisture is also affected by convective closure assumption and boundary conditions.

Recognizing the strengths and weaknesses of regional climate models across a spectrum of observations increases our confidence in the ability of RCMs to accurately downscale GCM data and improves our understanding of atmospheric dynamics and surface physics. In the companion paper, the models evaluated above are used to assess changes in the energy and water budgets of the American Midwest under multiple future climate scenarios.

Acknowledgments We thank the International Centre for Theoretical Physics, the Eltahir group, members of the Ralph M. Parsons Laboratory who aided in this research, our reviewers, and our editor. Individuals who made significant contributions to this work include Jeremy Pal and Marc Marcella. This work was funded by the National Science Foundation (Award EAR-04500341) and the Martin Family Fellowship.

\section{References}

Arakawa A, Schubert WH (1974) Interaction of a cumulus cloud ensemble with large-scale environment, part 1. J Atmos Sci 31:674-701

Bartlein P (2000) Absolute minimum temperature minus average of the coldest monthly mean temperature, sources include: Worldwide Airfield Summaries (NCDC TD-9647), Climatology of the U.S., No 20 (1951-80)

Bell JL, Sloan LC, Snyder MA (2004) Regional changes in extreme climatic events: a future climate scenario. J Clim 17:81-87

Davies H, Turner R (1977) Updating prediction models by dynamical relaxation: an examination of the technique. Q J R Meteorol Soc 103:225-245

Delworth TL, Stouffer RJ, Dixon KW, Spelman MJ, Knutson TR, Broccoli AJ, Kushner PJ, Wetherald RT (2002) Review of simulations of climate variability and change with the GFDL R30 coupled climate model. Clim Dyn 19:555-574

Dickinson R, Henderson-Sellers A, Kennedy P (1993) Biosphere Atmosphere Transfer Scheme (BATS) version 1E as coupled to the NCAR community climate model. Technical Note TN387+STR, National Center for Atmospheric Research

Diffenbaugh NS, Ashfaq M, Shuman B, Williams JW, Bartlein PJ (2006) Summer aridity in the United States: response to midholocene changes in insolation and sea surface temperature. Geophys Res Lett 33:L22712

Foley JA, Prentice IC, Ramankutty N, Levis S, Pollard D, Sitch S, Haxeltine A (1996) An integrated biosphere model of land surface processes, terrestrial carbon balance, and vegetation dynamics. Glob Biogeochem Cycles 10:603-628
Fritsch JM, Chappell CF (1980) Numerical prediction of convectively driven mesoscale pressure systems. Part I: convective parameterizations. J Atmos Sci 37:1722-1733

Grell GA, Dudhia J, Stauffer D (1994) A description of the fifthgeneration Penn State/NCAR Mesoscale Model (MM5). Technical Note TN-398+IA, National Center for Atmospheric Research

Kanamitsu M, Ebisuzaki W, Woollen J, Yang SK, Hnilo JJ, Fiorino M, Potter GL (2002) NCEP/DOE AMIP-II reanalysis (R-2). Bull Am Meteorol Soc 83:1631-1643

Liang XZ, Li L, Kunkel KE, Ting M, Wang JXL (2004) Regional climate model simulation of U.S. precipitation during 1982-2002. Part i: annual cycle. J Clim 17:3510-3529

Liang XZ, Pan J, Zhu J, Kunkel KE, Wang JXL, Dai A (2006) Regional climate model downscaling of the U.S. summer climate and future change. J Geophys Res 111:D10108

Manabe S, Wetherald RT, Milly PCD, Delworth TL, Stouffer RJ (2004) Century-scale changes in water availability: $\mathrm{CO}_{2}$ quadrupling experiment. Clim Change 64:59-76

Martínez-Castro D, Porfirioda Rocha R, Bezanilla-Morlot A, AlvarezEscudero L, Reyes-Fernández JP, Silva-Vidal Y, Arritt RW (2006) Sensitivity studies of the regcm 3 simulation of summer precipitation, temperature and local wind field in the Caribbean region. Theor Appl Climatol 86:5-22

Mitchell TD, Carter TR, Jones PD, Hulme M, New M (2004) A comprehensive set of high resolution grids of monthly climate for Europe and the globe: the observed record (1901-2000) and 16 scenarios (2001-2100). Tyndall Working Paper 55, URL http:// www.cru.uea.ac.uk/

NASA (2006) Surface radiation budget. online, URL http://eosweb. larc.nasa.gov

New M, Hulme M, Jones PD (1999) Representing twentieth century space-time climate variablility. Part 1: development of a 1961-90 mean monthly terrestrial climatology. J Clim 12:829856

Pal JS (2001) Modeling the role of soil moisture in North American summer climate. $\mathrm{PhD}$ thesis, Massachusetts Institute of Technology

Pal JS, Small EE, Eltahir EAB (2000) Simulation of regional-scale water and energy budgets: representation of subgrid cloud and precipitation processes within RegCM. J Geophys Res 105: 29579-29594

Pal JS, Giorgi F, Bi X (2004) Consistency of recent European summer precipitation trends and extremes with future regional climate projections. Geophys Res Lett 31:L13202

Pal JS, Giorgi F, Bi X, Elguindi N, Solmon F, Gao X, Rauscher SA, Francisco R, Zakey A, Winter J, Ashfaq M, Syed FS, Bell JL, Diffenbaugh NS, Karmacharya J, Konaré A, Martinez D, Da Rocha RP, Sloan LC, Steiner AL (2007) Regional climate modeling for the developing world: the ICTP RegCM3 and RegCNET. Bull Am Meteorol Soc 88:1395-1409

Ramankutty N (1999) Estimating historical changes in land cover: North American croplands from 1850 to 1992. Glob Ecol Biogeogr 8:381-396

Randall DA, Wood RA, Bony S, Colman R, Fichefet T, Fyfe J, Kattsov V, Pitman A, Shukla J, Srinivasan J, Stouffer RJ, Sumi A, Taylor KE (2007) Climate models and their evaluation. In: Climate change 2007: the physical science basis. Contribution of working group I to the fourth assessment report of the intergovernmental panel on climate change. Cambridge University Press

Reynolds RW, Rayner NA, Smith TM, Stokes DC, Wang W (2002) An improved in situ and satellite SST analysis for climate. J Clim 15:1609-1625

Roeckner E, Bäuml G, Bonaventura L, Brokopf R, Esch M, Giorgetta M, Hagemann S, Kirchner I, Kornblueh L, Manzini E, Rhodin A, 
Schlese U, Schulzweida U, Tompkins A (2003) The atmospheric general circulation model ECHAM5. Part I: model description. Tech. rep., Max-Plank Institute for Meteorology

Roeckner E, Lautenschlager M, Esch M (2006a) IPCC-AR4 MPIECHAM5_T63L31 MPI-OM_GR1.5L40 20C3M run no.3: atmosphere monthly mean values MPImet/MaD Germany. Tech. rep., World Data Center for Climate

Roeckner E, Lautenschlager M, Schneider H (2006b) IPCC-AR4 MPI-ECHAM5_T63L31 MPI-OM_GR1.5L40 SRESA1B run no.3: atmosphere monthly mean values MPImet/MaD Germany. Tech. rep., World Data Center for Climate

Seneviratne SI, Pal JS, Eltahir EAB, Schär C (2002) Summer dryness in a warmer climate: a process study with a regional climate model. Clim Dyn 20:69-85

Tchotchou L, Kamga F (2010) Sensitivity of the simulated African monsoon of summers 1993 and 1999 to convective parameterization schemes in regcm3. Theor Appl Climatol 100:207-220

USGS (1996) Global 30-Arc Second Elevation Dataset (GTOPO30). online, URL http://edc.usgs.gov/products/elevation/gtopo30/ gtopo30.html

USGS (1997) Global land cover characterization. online, URL http://edcsns17.cr.usgs.gov/glcc/
Wang G (2005) Agricultural drought in a future climate: results from 15 global climate models participating the the 4th assessment. Clim Dyn 25:739-753

Winter JM, Pal JS, Eltahir EAB (2009) Coupling of integrated biosphere simulator to regional climate model version 3. J Clim 22:2743-2757

Yeh PJF (2003) Representation of water table dynamics in a land surface scheme: observations, models, and analyses. $\mathrm{PhD}$ thesis, Massachusetts Institute of Technology

Yeh PJF (2005) Representation of water table dynamics in a land surface scheme. Part I: model development. J Clim 18:18611880

Yeh PJF, Irizarry M, Eltahir EAB (1998) Hydroclimatology of Illinois: a comparison of monthly evaporation estimates based on atmospheric water and soil water balance. J Geophys Res 103:19823-19837

Zanis P, Douvis C, Kapsomenakis I, Kioutsioukis I, Melas D, Pal J (2009) A sensitivity study of the regional climate model $($ regcm 3$)$ to the convective scheme with emphasis in central eastern and southeastern Europe. Theor Appl Climatol 97:327337 